\title{
Uncertainty in Future Summer Precipitation in the Laurentian Great Lakes Basin: Dynamical Downscaling and the Influence of Continental-Scale Processes on Regional Climate Change ${ }^{\mathfrak{O}}$
}

\author{
W. Richard Peltier, Marc d'Orgeville, Andre R. Erler, And Fengyi Xie \\ University of Toronto, Toronto, Ontario, Canada
}

(Manuscript received 19 June 2017, in final form 16 November 2017)

\begin{abstract}
Physics-based miniensembles of Weather Research and Forecasting (WRF) Model configurations have been employed to investigate future precipitation changes over the Great Lakes basin of eastern North America. All physics configurations have been employed to downscale multiple distinct Community Earth System Model, version 1 (CESM1), simulations driven by the representative concentration pathway 8.5 (RCP8.5) radiative forcing scenario, spanning a range from moderate (2045-60) to considerable (2085-2100) climate change. Independent of the physics configuration employed, all projected future precipitation changes are characterized by a general increase and a fattening of the tail of the daily rainfall distribution by the end of the century. The fattening of the tail can however be masked by natural variability in the case of the moderate warming expected by midcentury. The heavy-rainfall-derived precipitation increase is projected to be larger than or equal to the Clausius-Clapeyron thermodynamic reference of $7 \%$ increase per degree Celsius of surface warming, whereas the increase of average-rainfall-based precipitation becomes limited only for the largest global warming projections. This limitation is dramatically illustrated in one physics configuration at the end of the century. By downscaling the results obtained from the initial-condition ensemble, it is demonstrated that the extreme drying of the Great Lakes basin region characteristic of the most extreme end member of the CESM1 ensemble is significantly modified by downscaling with the version of WRF coupled to the Freshwater Lake model (FLake) of lake processes. This result does, however, depend upon the physics configuration employed in WRF for the parameterization of processes that cannot be explicitly resolved.
\end{abstract}

\section{Introduction}

With more than $20 \%$ of the total global supply of surface freshwater, the Great Lakes of eastern North America also have a substantial effect on the local climate of the region. As is the case with any large body of water, the collective effect of the Great Lakes tends to reduce the amplitude of diurnal and annual temperature variability; however, they also interact strongly with the dry cold airmass outflows from the Arctic, which leads to an increase in cloud cover and precipitation in winter, whereas in summer their influence tends to stabilize the local atmospheric boundary layer, which reduces convective cloud and rainfall. In fact, their influence on climate is

\footnotetext{
Supplemental information related to this paper is available at the Journals Online website: https://doi.org/10.1175/JCLI-D-170416.s1.
}

Corresponding author: W. R. Peltier, peltier@atmosp.physics. utoronto.ca strongly dependent on the competition between distinctly different air masses that cover the region at different times: dry, cold Arctic air from the north; mild, humid Pacific air from the west, or extremely moist and warm tropical air from the Gulf of Mexico to the south. To adequately investigate future climate change over the Great Lakes region, it is therefore necessary to take into account both local climate processes that directly involve the lakes and future changes in the large-scale circulation.

To this end, increasingly numerous and technically demanding climate simulations are being conducted over the Great Lakes region using a state-of-the-art regional climate model (RCM) at high resolution that explicitly resolves the influence of the lakes (e.g., Gula and Peltier 2012; see also Cox 1917; Bates et al. 1993; Lofgren 1997; Scott and Huff 1997; Notaro et al. 2013; Xiao et al. 2016) and that is driven by the dynamical downscaling of the global-scale future climate projections derived from the application of global coupled models (GCMs). In a further study in this continuing series (d'Orgeville et al. 2014; see also Notaro et al. 2015a,b), 
a physics-based miniensemble of simulations driven by a single GCM projection based upon the use of the National Center for Atmospheric Research (NCAR) Community Earth System Model, version 1 (CESM1), was employed to provide an initial analysis of the expected future changes in both average and extreme precipitation events. This further analysis of RCM downscaling-based projections of uncertainties in future climate change over the Great Lakes basin demonstrated that the expected future increase in average rainfall intensity in the region accurately followed the Clausius-Clapeyron thermodynamics-based reference of $7 \%$ increase per degree Celsius of surface warming at midcentury, independently of the RCM physics parameterizations employed. Insofar as the global-warminginduced impact upon rainfall extremes is concerned, however, this analysis strongly suggested that daily rainfall extremes would be expected to exceed the increase in strength that would be suggested on the basis of the same thermodynamic argument.

Because precipitation changes in one place have to be balanced by evaporation changes elsewhere, it has been shown that the change in the strength of the global hydrological cycle does not follow the Clausius-Clapeyron scaling and is instead in the range from $1 \%$ to $4 \%$ increase per degree Celsius of global surface warming as a consequence of energetic constraints (e.g., Allen and Ingram 2002). Despite this constraint on the strength of the global hydrological cycle, the changes in globalmean column-integrated water vapor scales very well with Clausius-Clapeyron-based expectations. A consequence of this is that numerous aspects of the climate response to greenhouse gas increase are found to be robustly and tightly coupled to the Clausius-Clapeyron scaling, as for instance is the associated enhancement of the spatial pattern of evaporation minus precipitation (Held and Soden 2006). In contrast, local changes in precipitation have for the most part been analyzed in terms of the regional water vapor budget, sometimes in relation to changes in the horizontal energy transport (Muller and O'Gorman 2011). To identify the root causes of average precipitation change, studies have decomposed them into dynamic and thermodynamic components, the former related to atmospheric circulation changes and the latter related to water vapor changes. Although such a decomposition is not unique, the use of this framework has led to the conclusion that the simulated increase of precipitation in the midlatitudes is primarily explained by the thermodynamic component (Emori and Brown 2005; Seager et al. 2010).

Changes in extreme precipitation have also been analyzed in terms of two possible mechanisms, similar to the dynamic versus thermodynamic argument for average precipitation. Extreme precipitation changes tend to scale as predicted by the Clausius-Clapeyron scaling in numerous regions whereas average precipitation changes do not (Tebaldi et al. 2006; Kharin et al. 2007, 2013), which is in accord with the general understanding that increased moisture content will contribute to increased precipitation intensity whereas total precipitation change will be dependent on water availability and the increased probability of drought in summer (Meehl et al. 2000). Our analysis will explicitly compare the projected changes in the intensity of extremes with the changes in averaged precipitation, and more importantly the sensitivity to temperature changes of both. In this context, the Clausius-Clapeyron-based expectation of a $7 \%$ increase per degree Celsius of surface warming will be used as a reference to detect changes in precipitation intensity, which are most likely thermodynamically driven.

To better constrain the model uncertainty involved in such future climate change projections, the initial physics-based miniensemble of future simulations employed in d'Orgeville et al. (2014) is expanded in the present paper through the addition of a new series of dynamically downscaled simulations based upon the use of an extended series of global-scale projections derived from the same coupled climate model but using different initial conditions. This initial-conditions-based miniensemble will be employed to complement the previous physics-based miniensemble, which is moreover extended to include two distinct time horizons, namely, for both the middle and the end of the twenty-first century. Expanding the datasets employed as basis for analysis in this way will enable us to incorporate the influence of the three sources of uncertainty that bedevil the problem of climate change projection, namely, those related to model sensitivity, those related to the natural variability of the climate system, and those related to the scenario employed to describe the trajectory of future greenhouse gas emissions [e.g., see Hawkins and Sutton (2009) for additional discussion], by employing, respectively, multiple assumptions concerning the representations employed for subgrid-scale physics in the RCM, multiple large-scale simulations derivative of projections made using a single GCM, and multiple time horizons over which the future projections are made.

\section{Models, simulations, and climate change projections}

The RCM employed throughout this study is the Weather Research and Forecasting (WRF) Model, version 3.4.1, with the Advanced Research WRF (ARW) dynamical core (Skamarock et al. 2008), which is now fully coupled to the Freshwater Lake model (FLake) (Mironov 2008) as in d'Orgeville et al. (2014), 
TABLE 1. Selected parameterizations of the five different WRF physics configurations.

\begin{tabular}{llll}
\hline \hline Configuration & Microphysics & Cumulus scheme & Land model \\
\hline $\mathrm{T}$ & WSM6 & Kain-Fritsch & Noah LSM \\
$\mathrm{M}$ & Morrison & Kain-Fritsch & Noah LSM \\
$\mathrm{m}$ & - & - & Noah MP \\
$\mathrm{G}$ & Morrison & Grell-3 & Noah LSM \\
$\mathrm{g}$ & - & - & Noah MP \\
\hline
\end{tabular}

whereas in the study by Gula and Peltier (2012), the FLake model was run only offline. The five different WRF physics configurations (Table 1) employed in the analyses to be discussed herein are the same as those employed by d'Orgeville et al. (2014). These different physics configurations include the Rapid Radiative Transfer Model for General Circulation Models (RRTMG) scheme for radiation (Iacono et al. 2008); the Mellor-Yamada-Nakanishi-Niino level-2.5 scheme for planetary boundary layer parameterization (Nakanishi and Niino 2009); either the WRF single-moment 6-class (WSM6; Hong and Lim 2006) or the Morrison et al. (2009) scheme for microphysics; either the Kain-Fritsch scheme (Kain 2004) or the Grell-3 scheme (Grell and Dévényi 2002) for cumulus parameterization; and either the Noah land surface model (Noah LSM; Chen and Dudhia 2001) or the Noah LSM with multiparameterization (MP) options (Niu et al. 2011) for land processes. The early paper of Liang et al. (2012) has commented upon the importance of the fact that WRF has continued to support multiple parameterization schemes for unresolved physical process as this capability may be invoked to build "physics ensembles" of the kind employed in the present paper. This provides a means of more accurately estimating the uncertainty associated with forward projections of the strength of the warming process at the regional scale. It will be important to understand that the greenhouse gas components of the forcing are exactly the same in both CESM1 and WRF as is the short wavelength insolation forcing. The sole exception to this commonality of forcing between the models concerns the aerosol component. Whereas CESM1 includes a specified sulfate aerosol forcing, WRF does not. It remains a significant challenge to the community to incorporate a regionally specified aerosol forcing in the downscaling of global warming results to the regional scale. We will comment upon whether the exclusion of this component of the forcing might be contributing to model bias in the discussion to follow.

The dynamical downscaling follows exactly the same two-step nesting procedure employed by both Gula and Peltier (2012) and d'Orgeville et al. (2014) in which the
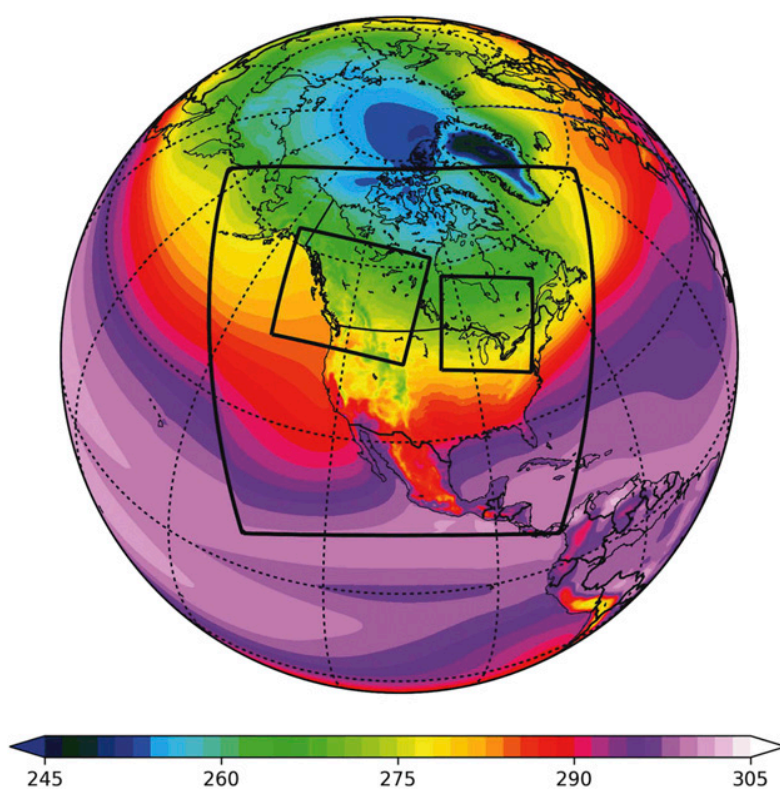

FIG. 1. The configuration of the outermost regional climate model (WRF) domain, which encompasses almost entirely the North American continent, as well as two innermost domains, with one situated over western North America and the other over the GLB of eastern North America. In the outermost domain the resolution of WRF is $30 \mathrm{~km}$ whereas in the innermost domain the resolution is $10 \mathrm{~km}$. The shading shows the annual average temperature $(\mathrm{K})$.

first nested outer domain is of North American continental scale at $30-\mathrm{km}$ resolution, whereas the innermost domain at $10-\mathrm{km}$ resolution covers the Great Lakes basin (GLB) and extends into the northern portion of the Canadian province of Ontario in the James Bay region. A detailed discussion of the downscaling pipeline that we employ is provided in Erler (2015). Figure 1 situates the innermost GLB domain within the continental-scale outermost WRF domain. Figure 1 also illustrates the positioning of a second innermost WRF domain that has been employed in the recent analyses of Erler et al. (2015) and Erler and Peltier $(2016,2017)$ of dynamically downscaled global warming projections for western Canada. Our further analyses of the Great Lakes basin region are relying upon the same global CESM1 initial-condition ensemble-based integrations as those that have been employed for analysis of highresolution climate change projections for the westernmost region of the continent in the papers of Erler et al. (2015) and Erler and Peltier (2016, 2017). As in Gula and Peltier (2012), the domain specified lateral boundary is composed of a 1-point specified zone and a 9-point relaxation (buffer) zone. Boundary conditions at the specified zone are determined entirely by temporal interpolation from the 6-h CESM1 data. Lateral boundary conditions in the relaxation zone are nudged toward the 
forcing data using the method of Davies and Turner (1977), with higher nudging coefficients for grid points that are closer to the specified zone. Spectral nudging above the boundary layer has also been applied to prevent the drift of the phase of the longest-wavelength waves $(>2000 \mathrm{~km})$ away from those of the global model.

The single GCM that is employed to drive the dynamical downscaling experiments is the Community Earth System Model, version 1.0.4, in its default coupled configuration [see Gent et al. (2011) for a complete description of the atmosphere, ocean, sea ice and land models]. In this global model, land surface processes are represented by the Community Land Model, version 4 (CLM4). The CESM1 simulations employed in this study comprise a historical period driven by a combination of anthropogenic and natural forcing (18702005) and future periods following the representative concentration pathway 8.5 (RCP8.5) scenario (20062100). All CESM1 simulations were run at the default nominal $1^{\circ}$ resolution, whose performance for historical and future periods has been extensively described (e.g., Gent et al. 2011; Meehl et al. 2012).

Four CESM1 simulations (C0, C1, C2, and C3) have been dynamically downscaled for $15 \mathrm{yr}$ for one historical period (1979-94), one future midcentury period (204560 ), and one future period at the end of the century (2085-2100). Each of these four global simulations, which constitute the initial-condition (IC) ensemble that will serve as basis for application of the dynamical downscaling process, were also employed by Erler et al. (2015) and Erler and Peltier $(2016,2017)$ for the purpose of investigating downscaling results over western Canada and were initiated at year 1870 from initial conditions taken from different years of the 1000-yr preindustrial control simulation employed in Peltier and Vettoretti (2014) for their analyses of the DansgaardOeschger oscillation phenomenon.

The expected disappearance of summer Arctic sea ice, perhaps within the next 30 years (Wang and Overland 2012), is a possibility that could have significant consequences for Northern Hemisphere climate. Because reduction of sea ice area is one of the main drivers of future Arctic warming amplification and because none of the four CESM1 simulations employed here have projected such a suggested reduction in Arctic summer sea ice, we have also included a fifth CESM1 simulation (C0-SeaIce; Table 2) by branching at year 2006 from simulation $\mathrm{C} 0$, following the same RCP8.5 future scenario but with artificially lowered sea ice albedo, which was diminished by reducing the optical properties of the snow, bare ice, and melt pond surfaces. Because of the resulting discontinuity at year 2006 and of the potentially unrealistic sea ice thermodynamics, the $\mathrm{C} 0$-SeaIce
TABLE 2. List of CESM1 simulations, periods for which dynamical downscaling using WRF has been performed and WRF physics configuration employed.

\begin{tabular}{lccc}
\hline \hline & 1979-94 & 2045-60 & 2085-2100 \\
\hline C0 & T, M, m, G, & T, M, m, G, & T, M, m, G, \\
& and g & and \\
a & and \\
C1 & T, M, and G & T, M, and G & $\mathrm{G}^{\mathrm{c}}$ \\
C2 & T and G & T and G & $\mathrm{G}^{\mathrm{c}}$ \\
C3 & T and G & T and G & - \\
C0-SeaIce & - & T, M, m, G, & - \\
& & and g &
\end{tabular}

${ }^{\text {a }}$ Ensembles employed by d'Orgeville et al. (2014).

${ }^{\mathrm{b}}$ New physics ensembles.

${ }^{\mathrm{c}}$ Simulations only run for the North American outer domain.

simulation is not intended to provide a faithful continuous climate projection but has been included in the analyses discussed herein only to provide climate boundary conditions by midcentury corresponding to an almost complete disappearance of Arctic sea ice during summer. The result is a midcentury projection slightly warmer than the $\mathrm{C} 0$ simulation but still with a much smaller temperature increase at the end of the century, in both summer and winter (Fig. 2 and Fig. S1 in the supplemental material). To fully appreciate the significance of the sample of the continental-scale forward projections of summer 2-m average temperature results relative to the modern control integration shown in Fig. 2, obtained by downscaling into the outermost WRF domain, it is important to consider the question of model bias, an issue to which we will turn almost immediately. Before doing so, however, we note the dramatic contrast shown in Fig. $2 \mathrm{~b}$ between the warming projected at the end of the century and that at midcentury derived from all the members of the physics ensemble. We also note the evident increase in midcentury warming in the downscaled results from the global $\mathrm{C} 0$-SeaIce run in which sea ice has been eliminated from the Arctic Ocean.

Because this would otherwise have been excessively computationally expensive, each member of the CESM1 initial-condition ensemble has not been downscaled using all five WRF physics configurations. Instead, as summarized in Table 2, the simulation matrix (WRF physics configurations-CESM1 simulations-future periods of projection) has been designed to focus on the results from the initial-condition ensembles for both the $\mathrm{T}$ and $\mathrm{G}$ physics configurations for the midcentury period, which includes all four CESM1 simulations $[\mathrm{C} 0+$ $\mathrm{C} 1+\mathrm{C} 2+\mathrm{C} 3 / 2045-60]$, and three physics ensembles at different time horizons for which all five WRF physics configurations were employed, namely, [C0/2045-60], [C0-SeaIce/2045-60] and [C0/2085-2100]. For each projection member of those ensembles, the corresponding historical run (physics-CESM1 simulation-1979-94) will 
a) $[\mathrm{C} 0+\mathrm{C} 1+\mathrm{C} 2+\mathrm{C} 3 / 2045-2060]$ G-Physics and T-Physics
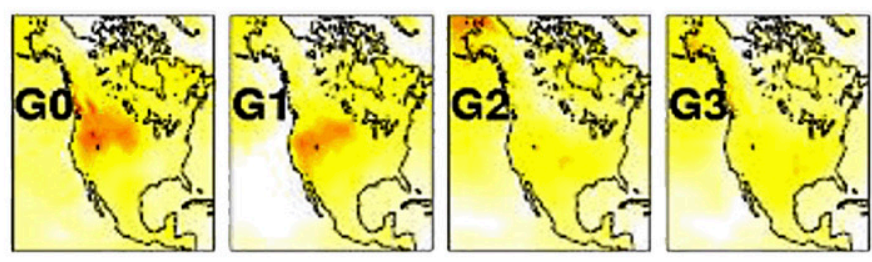

$-10 \quad 0 \quad 10 K$
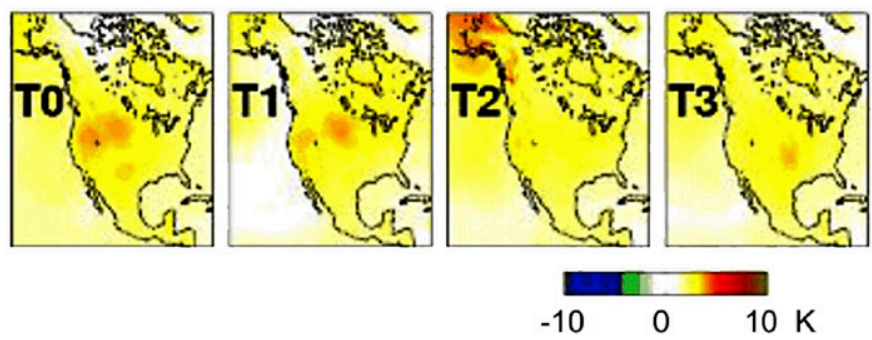

b) [C0/2045-2060], [C0-SeaIce/2045-2060] and [C0/2085-2100]
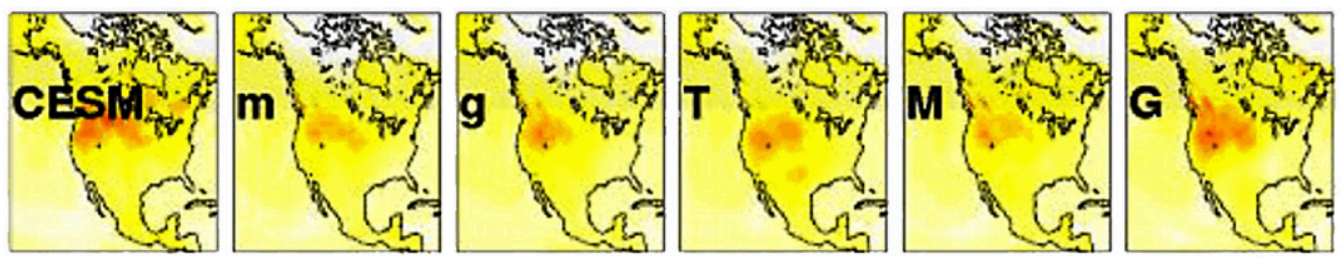

$-10 \quad 0 \quad 10 K$
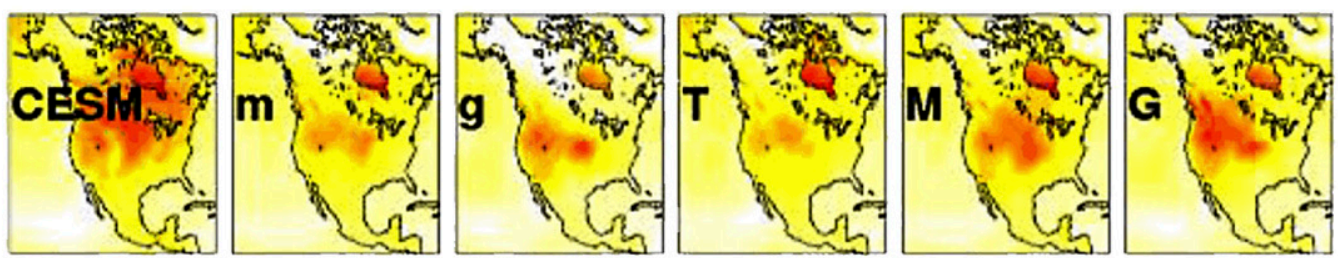

$-10 \quad 0 \quad 10 \mathrm{~K}$
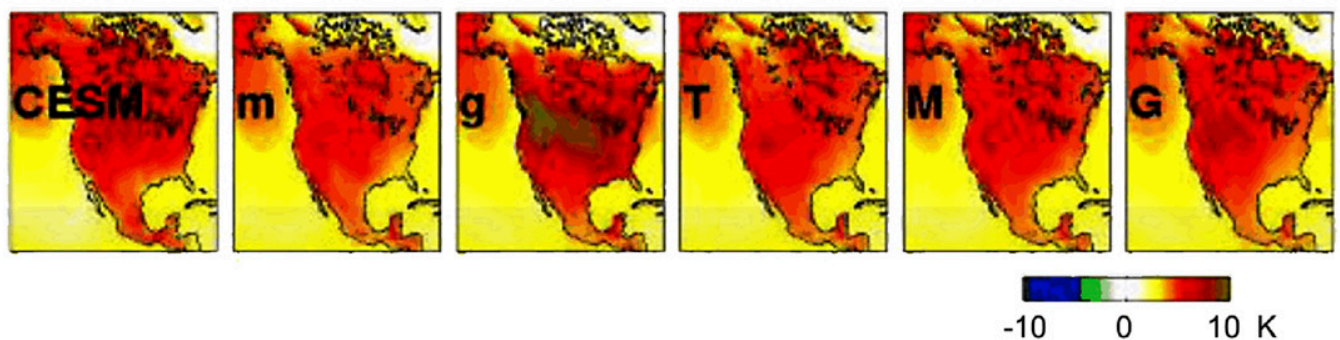

FIG. 2. Future summer temperature change (K) for each experiment for (a) the two IC ensembles with (top) $G$ and (bottom) $\mathrm{T}$ physics configurations and for (b) the three physics ensembles for future experiments (top) $\mathrm{C} 0$ midcentury, (middle) C0-SeaIce midcentury, and (bottom) C0 end of the century and for CESM1 simulation: (left)-(right) CESM1, m, g, T, M, and G simulations. 
be the reference on the basis of which the magnitude and nature of future climate change will be assessed.

Finally, note that the two physics ensembles, which were based on the CESM1 ensemble members [C0/ 1979-94] and [C0/2045-60], were the sole basis of the analysis by d'Orgeville et al. (2014), and as such the current matrix of simulations constitutes a very significant expansion of this initial analysis.

\section{Simulations of historical North American climate: The WRF outer domain}

A detailed assessment of the representation of the mean climate in the Great Lakes region inner domain was presented in d'Orgeville et al. (2014) for the historical physics ensemble [C0/1979-94]. The inclusion of the new historical simulations [C1 + C2 + C3/1979-94] for multiple physics confirmed the original assessment (d'Orgeville et al. 2014), and its conclusions will be repeated here only where necessary. Instead, because the focus of the present article will also include discussion of remote continental-scale influences upon the precipitation changes in the Great Lakes region, the assessment of the quality of the representation of the mean climate within the North American outermost WRF domain is presented as an important complement to the local influences: the seasonal and annual averages of the historical $\mathrm{C} 0$ simulations of the five physics configurations have been compared to the Climatic Research Unit (CRU) historical time series datasets, version 3.10 (TS3.10), for total precipitation (Harris et al. 2014) in Figs. 3 and 4 and to the North American Regional Reanalysis (NARR) data (Mesinger et al. 2006) for 2-m air temperature in Figs. 5 and 6. The box-and-whisker plots in Figs. 3 and 5 compare the distribution of differences from observational data at all grid points of the inner domain for annual, summer, and winter averages. The spatial pattern of these differences are plotted on Figs. 4 and 6 for the summer season only, with a focus on the physics ensemble. These data document the outer domain model biases in both precipitation and temperature in terms of which the meaningfulness of the forward projections shown on Fig. 2 are to be appreciated.

All simulations are characterized by a small annually averaged bias of total precipitation (solid plus liquid) averaged spatially over the surface of the North American continent, which is on the order of $0.3 \mathrm{~mm} \mathrm{day}^{-1}$ for $\mathrm{T}, \mathrm{M}$, and $\mathrm{m}$ physics-based simulations and $0.1 \mathrm{~mm}^{-1} \mathrm{day}^{-1}$ for $\mathrm{G}$ and $g$ physics-based simulations (Fig. 3). Annually averaged differences between the different physics configurations are explained primarily by the summer precipitation differences due to the different cumulus parameterization schemes employed: simulations $\mathrm{T}, \mathrm{M}$,

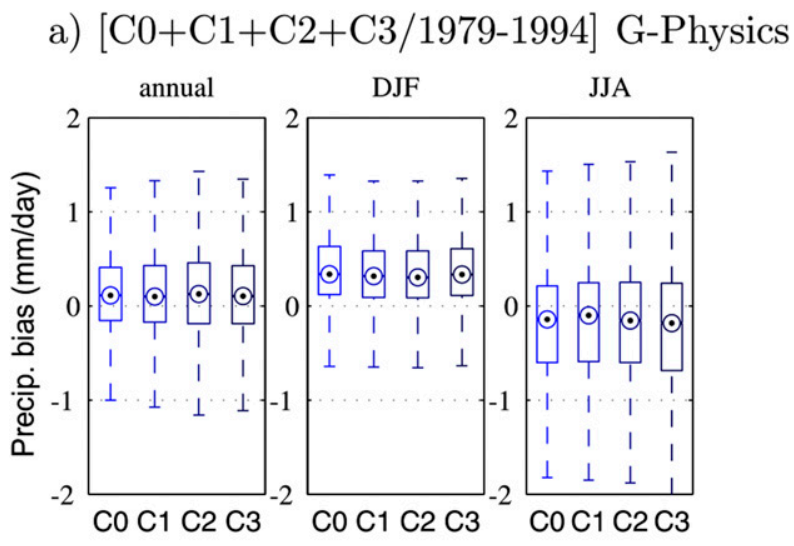

b) Physics ensemble: [C0/1979-1994]

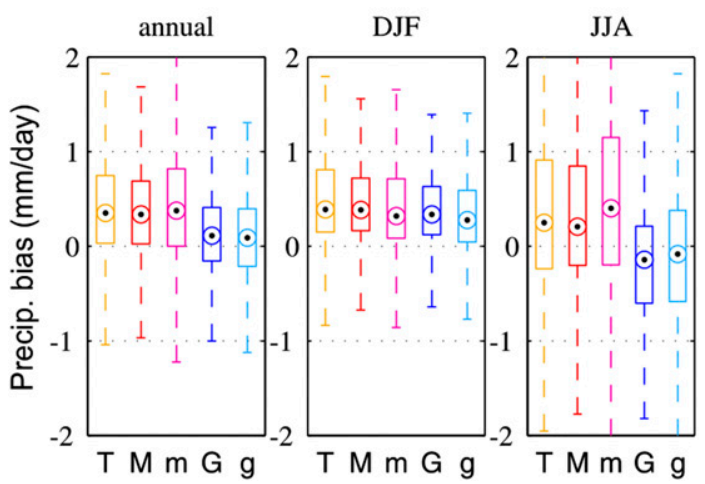

FIG. 3. Box-and-whisker plots of the gridcell-averaged precipitation differences between each historical simulation and the CRU dataset for the period 1979-94 $\left(\mathrm{mm} \mathrm{day}^{-1}\right)$ (a) for the historical IC ensemble with G physics and (b) for the physics ensemble. Differences in annual, winter, and summer averages are plotted. Each physics configuration is represented by a different color. The center of the box represents the median of the data points (50th percentile), the upper edge of the box represents the 75 th percentile (q3), and the lower edge the 25 th percentile (q1). The whiskers extend to the most extreme data points not considered outliers, where outliers are points located farther than $\pm 1.5 \mathrm{~mm} \mathrm{day}^{-1}$ ( $\left.\mathrm{q} 3-\mathrm{q} 1\right)$ from the edge of the box. For a normal distribution this would correspond to $\pm 2.7 \sigma$ and $99.3 \%$ coverage of the distribution.

and $\mathrm{m}$ with the Kain-Fritsch cumulus scheme tend to have significantly more precipitation in summer while simulations $\mathrm{G}$ and $\mathrm{g}$ with the Grell-3 scheme have a tendency to produce somewhat less summer precipitation (Fig. 3). The spatial patterns of these summer precipitation differences for the Kain-Fritsch cumulus scheme (configurations T, M, and m: Fig. 3) are characterized by a large excess over the eastern parts of Canada and the United States and an excess over the entire North American Cordillera on the western perimeter of the continent. In contrast, for simulations with the Grell-3 scheme (configurations $\mathrm{G}$ and g; Fig. 3), both western and eastern precipitation excesses are muted, whereas a lack 

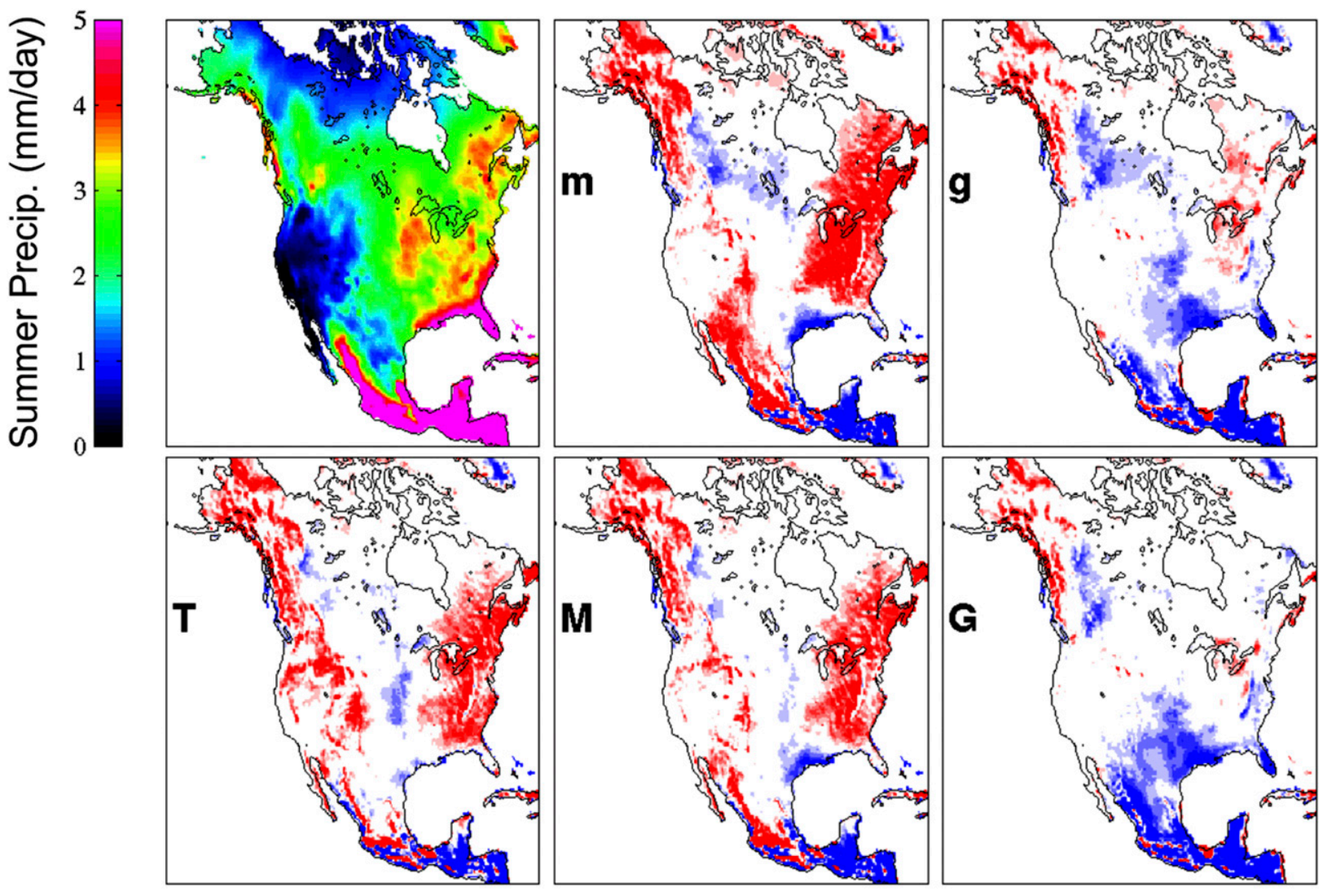

$-2$

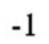

0

2

\section{Summer Precip. bias (mm/day)}

FIG. 4. (top left) Summer (JJA) average of precipitation from the CRU 1979-94 dataset, and JJA-averaged biases of the five simulations that constitute the WRF historical physics ensemble $\left(\mathrm{mm} \mathrm{day}^{-1}\right)$. The color bar at the top left is for the CRU summer-averaged precipitation, whereas the color bar at the bottom right is for the deviation from the CRU average produced by the individual members of the physics ensemble downscaled from the $\mathrm{C} 0$ member of the global initial-condition ensemble.

of precipitation in the south becomes evident, particularly over Mexico and the central southern United States. For the winter season, all simulations display the same order of magnitude of precipitation excess (Fig. 4; approximately $0.3 \mathrm{~mm} \mathrm{day}^{-1}$ in spatial average) with relatively small spatial differences between different physics configurations (Fig. S2 in the supplemental material). Despite some deficiencies, the Grell-3 configurations ( $\mathrm{G}$ and $\mathrm{g}$ ) can be said to provide the best representations of precipitation over the North American continent as a whole. A similar conclusion has already been drawn for the inner domain of the Great Lakes region (d'Orgeville et al. 2014).

In terms of temperature, all of the downscaled simulations, whether from the initial-condition ensemble or the physics ensemble, have a modest spatially averaged cold bias of $1^{\circ} \mathrm{C}$ or less over the outer domain (Fig. 5), with a larger cold bias generally over the continent, particularly in summer for simulations based upon use of the Grell-3 cumulus scheme ( $\mathrm{G}$ and g; Fig. 6) and in winter for simulation $\mathrm{T}$ with the WSM6 microphysics scheme (Fig. S3 in the supplemental material). This cold bias may be in part inherited from the parent global model; however, it is clearly magnified over the hightopography regions in the western part of the continent. Based upon the average of the bias over the surface of the continent, $\mathrm{T}, \mathrm{M}$, and $\mathrm{m}$ simulations can be considered to have the best representation of temperature. This conclusion is consistent with the results obtained for the inner domain over the Great Lakes region (d'Orgeville et al. 2014), although in this region configurations $\mathrm{m}$ and $\mathrm{M}$ are preferred over $\mathrm{T}$. It is important to draw attention here to the fact that the regional model we are employing does not include the 
a) $[\mathrm{C} 0+\mathrm{C} 1+\mathrm{C} 2+\mathrm{C} 3 / 1979-1994]$ G-Physics

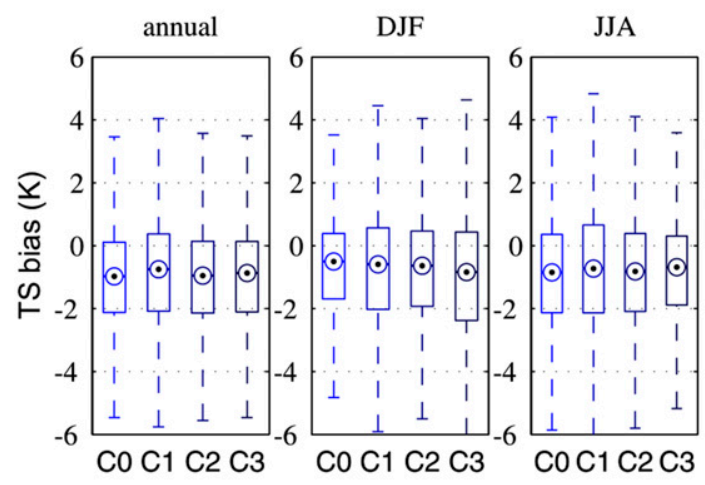

b) Physics ensemble: [C0/1979-1994]

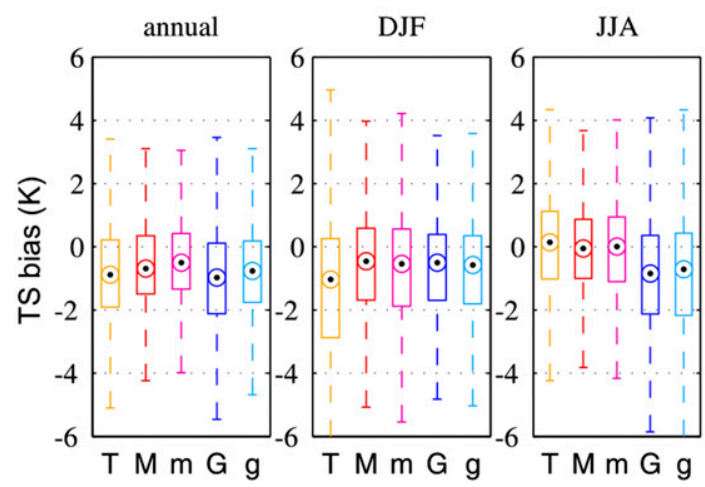

FIG. 5. As in Fig. 3, but for temperature (K) with observations from the NARR dataset.

influence of sulfate aerosol forcing whereas the global model does include this influence. If WRF were also to include explicit sulfate aerosol forcing we would expect the cold bias to be further exacerbated.

\section{a. Rainfall and precipitation changes in the Great Lakes region}

A primary motivation for this study has been to determine whether the findings of d'Orgeville et al. (2014) (obtained from the dynamical downscaling of $\mathrm{C} 0$ simulations at midcentury only) are robust to the influence of changes in internally generated climate variability at midcentury (as represented in the different members of the initial-condition ensemble) and to the different levels of warming expected at different future time horizons. More specifically, we wish to answer the following questions concerning the primary conclusion of that work that, in the GLB, the extremity of extreme precipitation events is expected to increase and the return time of events of a given extremity is expected to decrease. In particular, (i) is the previously projected future increase of precipitation robust against the changes in internal climate variability that are captured in the initial-condition ensemble? (ii) Is the previous projection of an increase by midcentury of heavy rainfall events similarly robust? (iii) Does the tail of the probability distribution of daily rainfall "fatten" as projected in these previous analyses based upon the physics ensemble? (iv) Does the accuracy of the ClausiusClapeyron projection of future rainfall intensity as a function of surface temperature increase remain valid in the GLB? The distinction between rainfall intensity changes presented in d'Orgeville et al. (2014) and average precipitation changes will also be addressed in what follows.

To begin to answer these central questions, Fig. 7 presents the changes in rainfall obtained for the future projections of the physics ensemble driven by $\mathrm{C} 0$ and $\mathrm{C} 0$-SeaIce by midcentury, and driven by $\mathrm{C} 0$ at the end of the century, as well as that obtained for the IC ensembles driven by $\mathrm{C} 0, \mathrm{C} 1, \mathrm{C} 2$, and $\mathrm{C} 3$ for both $\mathrm{G}$ and $\mathrm{T}$ physics configurations by midcentury. All physics configurations for all time horizons or CESM1 simulations show an unequivocal increase in rainfall, in both average and heavy precipitation ( $\delta \mathrm{Rain}_{\mathrm{tot}}$ and $\delta I^{H} ;$ Fig. 7). The increase in total precipitation (as opposed to rainfall) is smaller but still positive (not shown). The heavy rainfall intensity $\delta I_{r}^{H}$ is defined here as the average rainfall over the $2.7 \%$ largest daily rainfall events (corresponding to the 150 maximum values of a 15 -yr simulation, i.e., an average of 10 values per year of simulation). The increase in heavy precipitation is essentially the same as the increase in heavy rainfall, because heavy precipitation events are dominated by heavy rainfall events in summer. The increase in precipitation is therefore robust, which is consistent with global results obtained from the two most recent phases of the Coupled Model Intercomparison Project (CMIP3 and CMIP5) in terms of average and extreme precipitation change (Tebaldi et al. 2006; Kharin et al. 2007, 2013). Furthermore, it is evident that the increase in heavy rainfall is very close in magnitude to the increase in total rainfall. This is consistent with the results for western Canada of Erler and Peltier (2016), who show that the projected increase in precipitation extremes as a result of global warming does not significantly deviate from the projected increase in total precipitation for the same season.

At this point the reader should also be reminded that the box-and-whisker plots characterize the distribution of gridpoint changes across the entire inner domain, which includes the Great Lakes basin but also large parts of northern Ontario. As will be shown below, there is a tendency toward more precipitation increase in the northern regions and no increase or even a decrease in the southern half of the domain (the actual Great Lakes basin) for both total rainfall and heavy rainfall/precipitation. 

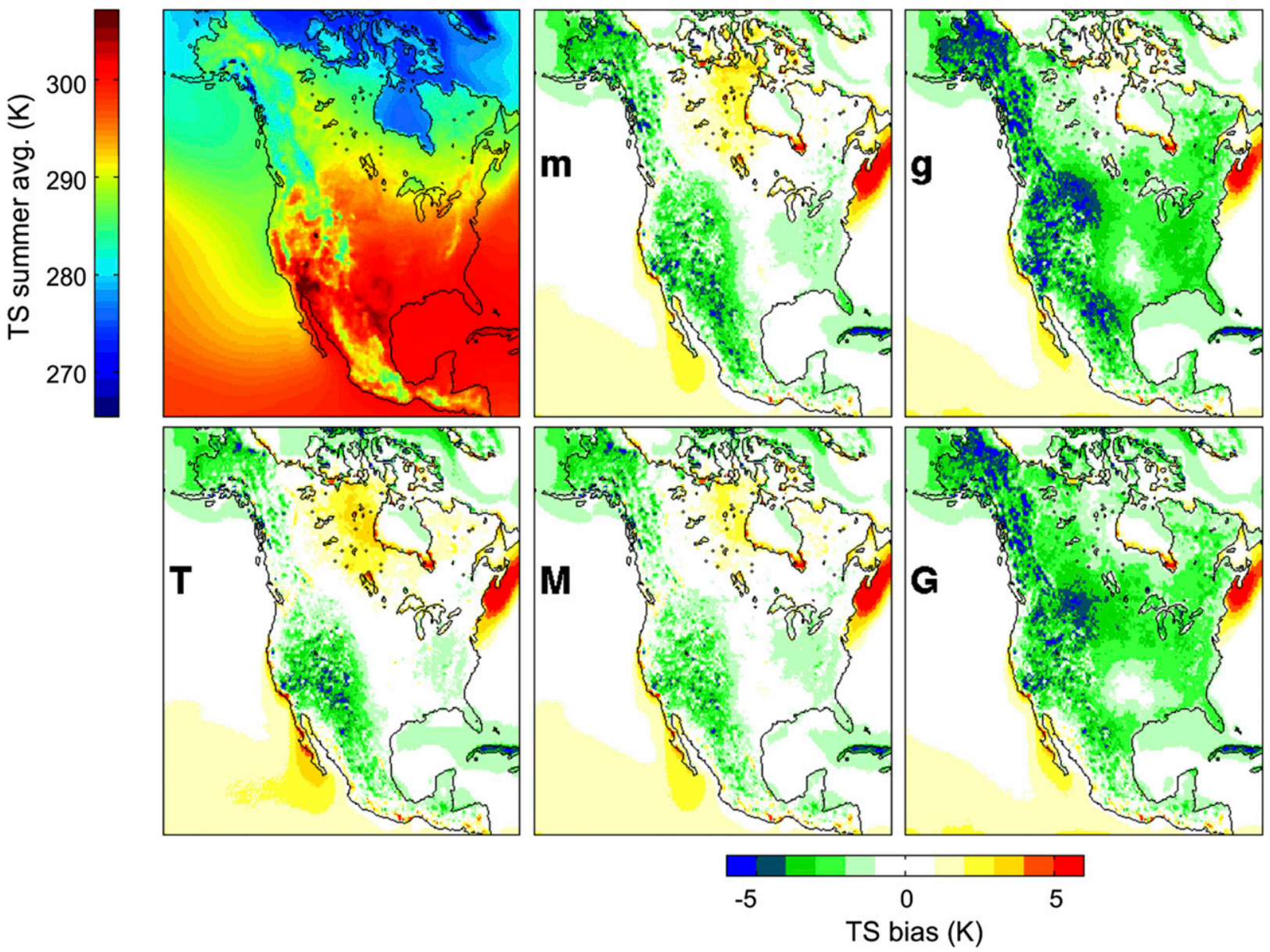

FIG. 6. As in Fig. 4, but for temperature (K) with observations from the NAAR dataset.

To investigate the shape of the tail of the daily rainfall distribution, the bottom row of Fig. 7 presents the future change in the ratio of the contribution of the $10 \%$ largest values of heavy rainfall events to the total of the heavy rainfall events (i.e., the contribution of the expected yearly maximum of daily rainfall $X_{1}$ to the expected total rainfall for one year from the 10 largest daily rainfall events: $\left.H_{10}=10 \times I_{r}^{H}\right)$. Globally, the results for all simulations show a tendency for an increase in the contribution of extremes. Considering the results for the physics ensembles for different time horizons (Fig. 7, right), the increase in the contribution of extremes is maximized at the end of the century when the strongest warming is occurring. However, when considering the IC ensembles of midcentury projections (Fig. 7, left), both physics configurations suggest that the contributions from the extremes can either increase or decrease slightly simply as a result of natural variability. The midcentury spread of extreme contribution change ( $\pm 1.5 \%$ for the median value) is on the order of the magnitude of the increase detected in the midcentury physics ensemble, casting doubt on the statistical significance of detecting such an increase by midcentury. This spread is however smaller than the end-of-the-century increase, therefore lending support to the global tendency toward an increase of the contributions of extremes. [Note that an extreme value analysis involving the fitting of the tail of each distribution with a generalized Pareto distribution or a generalized extreme value distribution would give the same qualitative result for the change in the shape parameter of the tail—see d'Orgeville et al. (2014) for a comparison.]

Although one cannot rule out decadal natural variability as being the cause of the fattening of the daily rainfall distribution by midcentury, there exist some differences in the projected changes between different numerical experiments that are particularly visible when analyzing the sensitivity of rainfall intensity to surface temperature changes, to be referred to as the ClausiusClapeyron (CC) sensitivity hereafter (Fig. 8). It must first be noted that the $\mathrm{CC}$ sensitivity values of the original C0 midcentury physics ensemble of d'Orgeville 

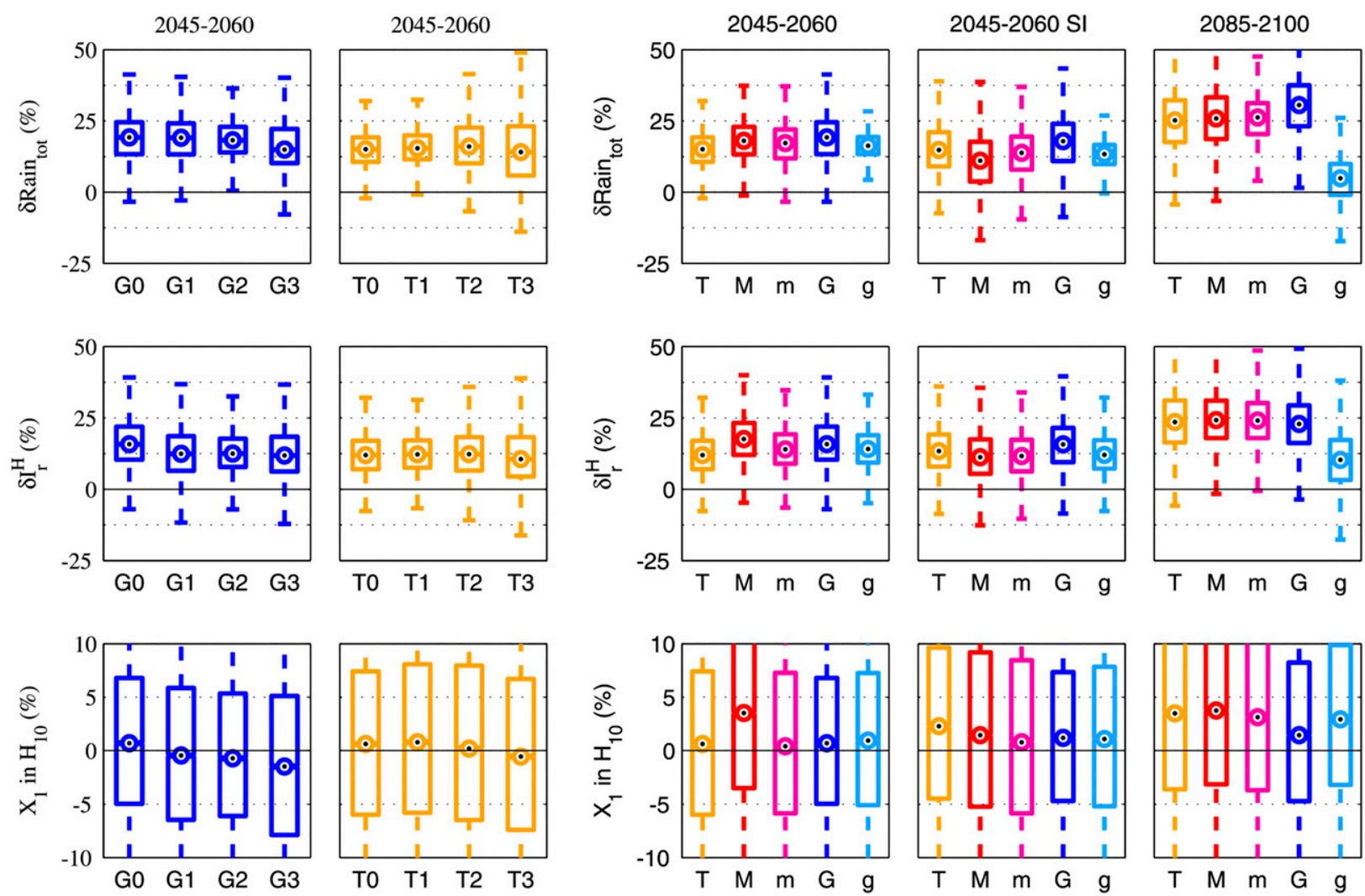

FIG. 7. Box-and-whisker plots of the rainfall changes in the inner domain over the GLB shown in Fig. 1, for the warm season (JJA) for each experiment of (left) the two IC ensemble members with the $\mathrm{G}$ and $\mathrm{T}$ physics configurations and (right) the three physics ensembles. (top)-(bottom) The indices plotted are $\delta \mathrm{Rain}_{\text {tot }}, \delta I_{r}^{H}$, and the change in the fatness of the tail of the daily distribution $\left(X_{1} / H_{10}\right)$ represented by the contribution of the expected yearly maximum of daily rainfall $X_{1}$ to the expected total rainfall for one year from the 10 largest daily rainfall events $\left(H_{10}=10 \times I_{r}^{H}\right)$.

et al. (2014) are not significantly different from the values obtained on the basis of the midcentury initialcondition ensemble (Fig. 8, right). This confirms that the projection of the future heavy rainfall increase as being larger than the Clausius-Clapeyron reference value for midcentury described by d'Orgeville et al. (2014) continues to be representative of expectations for a moderate level of future global warming (see "All" in Fig. 8, bottom right).

Second, when comparing the CC sensitivity between different levels of warming and time-horizon ensembles, the projected $\mathrm{CC}$ sensitivities are lower for the two warmest future ensembles, $\mathrm{C} 0$-SeaIce midcentury and $\mathrm{C} 0$ end of the century, when compared to the original $\mathrm{C} 0$ midcentury ensemble of d'Orgeville et al. (2014) (Fig. 8, dark gray box plots). On one hand, the average rainfall CC sensitivity $\left(\delta I_{r} / \delta \Delta T_{r}\right)$ becomes significantly less than the reference of $7 \%{ }^{\circ} \mathrm{C}^{-1}$ of warming for these two future ensembles, which suggests that the future increase in rainfall could potentially become restricted by the lack of moisture reaching the Great Lakes region for a sufficiently strong future global warming or polar amplified warming. On the other hand, the heavy rainfall CC sensitivity $\left(\delta I_{r}^{H} / \Delta T_{r}^{H}\right)$ also decreases for those two future ensembles but stays above or equal to the reference value of $7 \%{ }^{\circ} \mathrm{C}^{-1}$, with the reduction being possibly due to the same moisture restriction as for the average, the absence of enhancing mechanisms described by d'Orgeville et al. (2014), or a combination of both.

Third, there is one physics configuration that shows a strikingly enhanced decrease in terms of CC sensitivity for increasingly warm climate: configuration g (Fig. 8, light blue box plots), with a projected heavy rainfall CC sensitivity of only $4.7 \%{ }^{\circ} \mathrm{C}^{-1}$, which is significantly lower than the values above $7 \%{ }^{\circ} \mathrm{C}^{-1}$ of the other configurations, which in turn suggests that some moisture restriction can occur for strong warming. This simulation is also the only physics configuration that displays a distinct behavior for the end of the century with a projected increase of both total and heavy rainfall smaller for the end of the century than for midcentury simulations (Fig. 7, light blue), that is, a rainfall decrease in the 

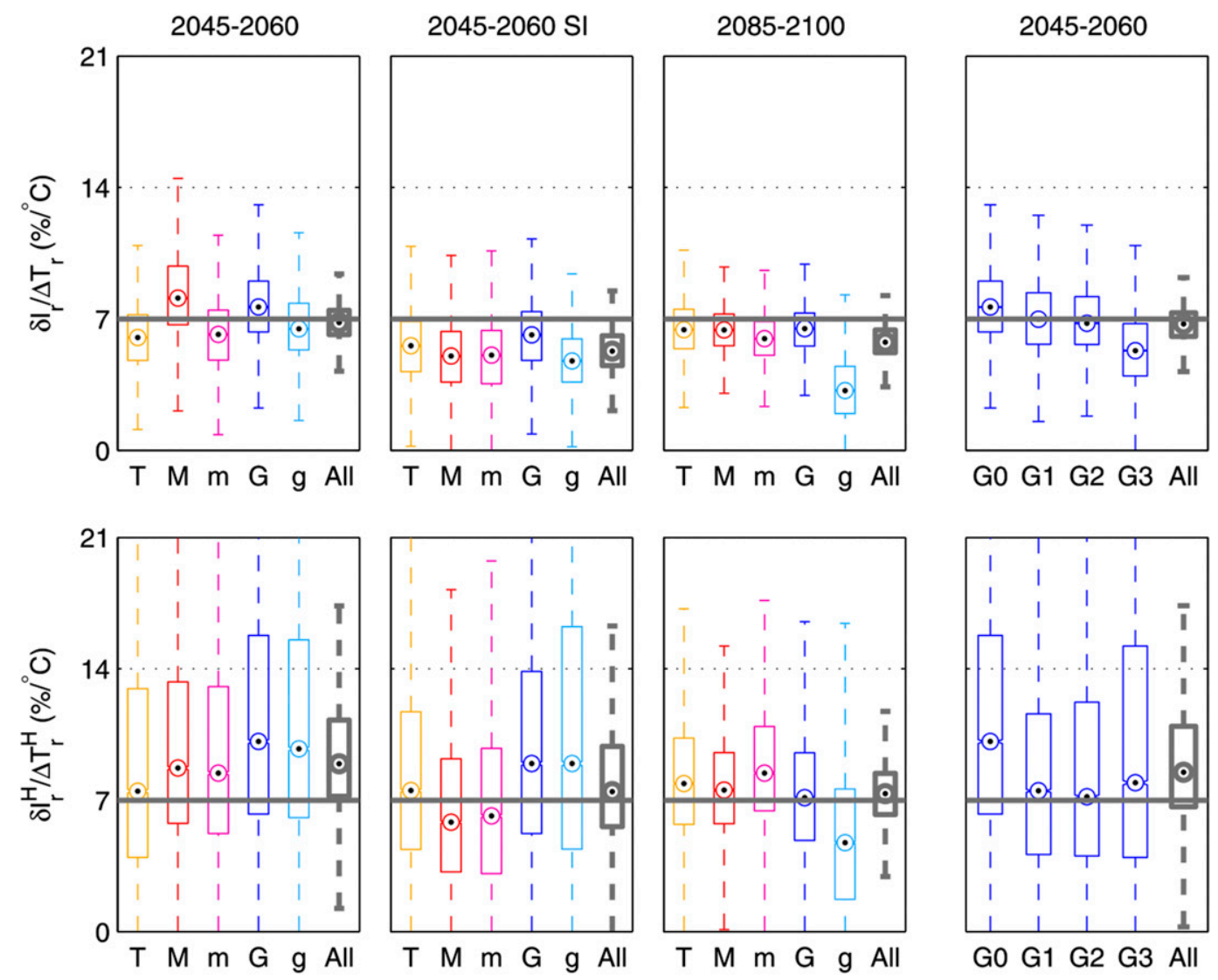

FIG. 8. Box-and-whisker plots of the CC temperature sensitivity (top) of $\delta I_{r} / \Delta T_{r}$ and (bottom) of $\delta I_{r}^{H} / \Delta T_{r}^{H}$ for (left)-(right) the $\mathrm{C} 0$ midcentury physics ensemble, the $\mathrm{C} 0$-SeaIce midcentury physics ensemble, the $\mathrm{C} 0$ end-of-thecentury physics ensemble and the $\mathrm{Gx} 4$ initial-condition ensemble. For each ensemble, all individual sensitivities for each experiment are shown, as well as the average sensitivity over the entire ensemble (in gray). The color scheme is as in Fig. 7.

second part of the century during which the North American climate is warming even more rapidly (Fig. 2). The next section will look more closely at how and why the rainfall-temperature relationship that could be anticipated from Clausius-Clapeyron alone fails to hold for configuration $g$ at the end of the century, and more importantly whether the projection produced by this configuration constitutes a plausible scenario. It is important to also emphasize that, despite the potentially strong moisture restriction that configuration $\mathrm{g}$ projects for the two warmest time horizons based on CC sensitivities, the tail of its daily rainfall distributions is still projected to fatten, which indicates that such restriction does not impact significantly the increase in the strength of future extreme rainfall events. In fact for all configurations, any potential moisture restriction seems to impact more strongly the average rainfall precipitation than the heavy rainfall events.

To this point, all results in this section have been presented for rainfall only. The current focus on the CC sensitivity of rainfall intensity has allowed us to compare directly the changes in CC sensitivity of average rainfall intensity and heavy rainfall events and to draw some conclusions concerning the changes in the tail of the daily rainfall distribution that are not solely due to the thermodynamic changes (Fig. 8; d'Orgeville et al. 2014). It is also common to look at the changes in terms of total precipitation. Because in the Great Lakes region rainfall-based precipitation dominates snowfall precipitation, the projection of total precipitation changes have the same characteristics as the rainfall changes in terms of increases in averages, in amplitude of extremes, and in the contribution of extremes (see Fig. S4 in the supplemental material compared to Fig. 7). However, Fig. 9 demonstrates that the CC sensitivity of the precipitation intensity $\left(\delta I_{p} / \Delta T_{p}\right)$ and of averaged total precipitation $\left(\delta \operatorname{Precip}_{\text {tot }} / \Delta T_{\text {tot }}\right)$ is only on the order of $4 \%$ and $3 \%{ }^{\circ} \mathrm{C}^{-1}$, respectively. Because relative changes in precipitation or rainfall average intensity are essentially the same (Figs. 7 and S4) the variation of the CC 

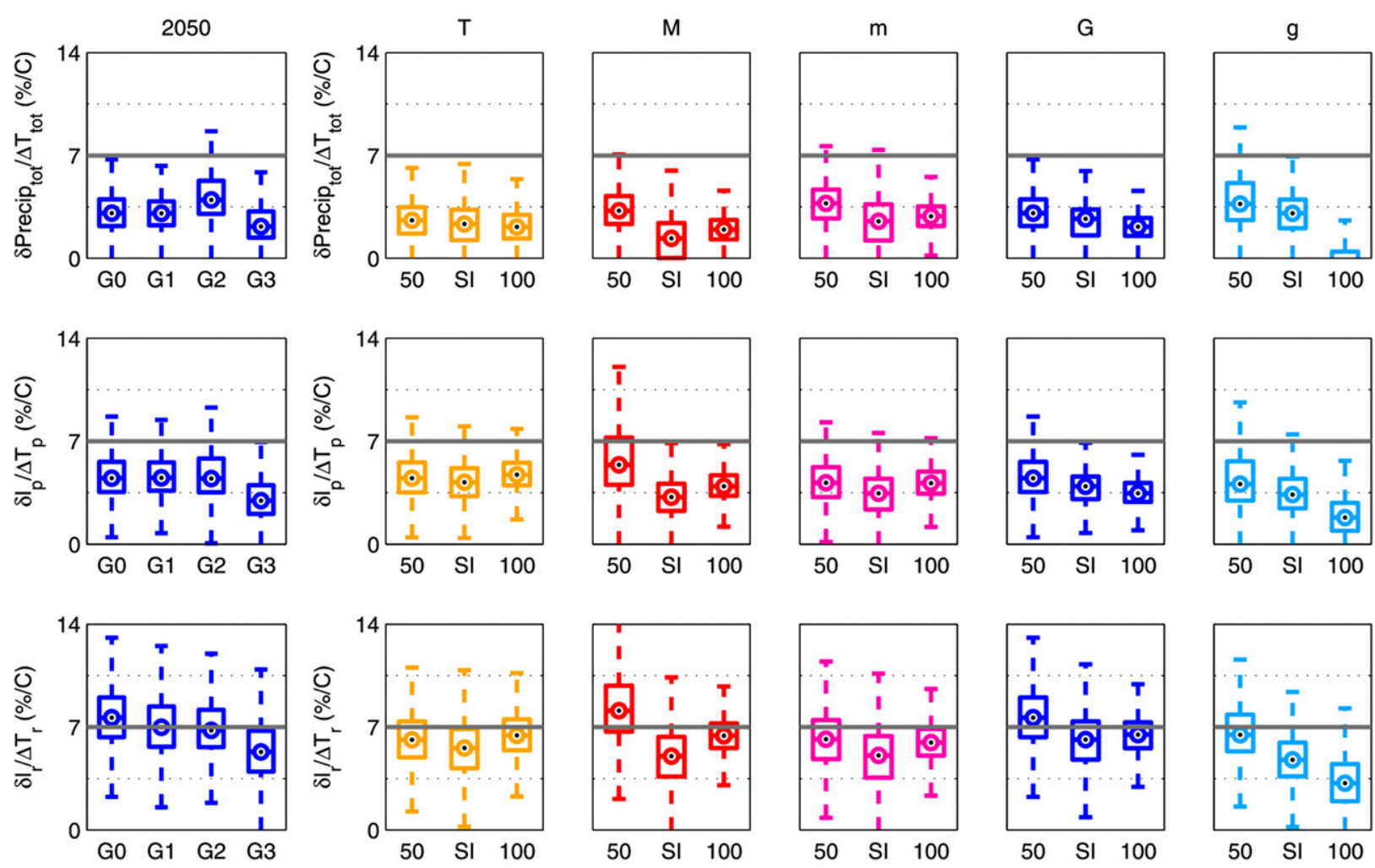

FIG. 9. Box-and-whisker plots of the $\mathrm{CC}$ temperature sensitivities $\left(\%{ }^{\circ} \mathrm{C}^{-1}\right)$ of all experiments (left) of the $\mathrm{IC}$ ensemble with $\mathrm{G}$ physics and (five right columns) of the three physics ensembles, grouped by the five physics configurations instead of time horizons. CC sensitivities are presented for the (top) averaged total precipitation, (middle) average precipitation intensity, and (bottom) average rainfall intensity.

sensitivities from $7 \%{ }^{\circ} \mathrm{C}^{-1}$ for rainfall to $4 \%{ }^{\circ} \mathrm{C}^{-1}$ for precipitation arises from a larger change in temperature. The future warming in cold seasons in the Great Lakes region is larger than in warmer seasons, so averaging over rainy and snowy days increases the temperature change and decreases the $\mathrm{CC}$ sensitivity compared to averaging only over rainy days.

\section{b. Seasonal precipitation changes in the Great Lakes region: The innermost WRF domain}

Consideration of the future total precipitation changes in the Great Lakes region on the seasonal time scale for the two IC ensembles (Fig. 10a) demonstrates that for midcentury, superimposed on a robust increase in precipitation for all seasons, there is also a large natural variability in seasonal change, which is for the most part driven by the GCM simulations; for instance the maximum seasonal precipitation change for both $\mathrm{G}$ and $\mathrm{T}$ physics configurations occurred in winter when driven by the $\mathrm{C} 1$ simulations, in spring when driven by the $\mathrm{C} 0$ and $\mathrm{C} 3$ simulations, and almost equally in winter, spring, and summer when driven by the $\mathrm{C} 2$ simulations. Despite this large decadal natural variability from the
CESM1 simulations it is also possible to distinguish some common characteristics of seasonal changes: the fall presents the least precipitation change across all CESM1 simulations, the winter the largest natural variability spread, the spring the most consistent increase, and the summer by far the largest spread (largest size of "the box" across all CESM1 simulations). Note, however, that the large spread in summer is not only the consequence of natural variability but is also due to the existence of a large-scale gradient in the change signal, the importance of which is further discussed in what follows.

When considering the physics ensembles (Fig. 10b) the same characteristics of seasonal changes are found for all time horizons as for the IC ensemble members, except that summer precipitation changes display a negative median value for some simulations. Two of the physics configurations project a median decrease of precipitation for the summer under the midcentury reduced sea ice scenario, and, more noticeably, configuration $\mathrm{g}$ projects a drastic decrease of precipitation for summer at the end of the century (almost $1 \mathrm{~mm}$ day $^{-1}$ in spatial average over the entire inner domain). This 
a) $[\mathrm{C} 0+\mathrm{C} 1+\mathrm{C} 2+\mathrm{C} 3 / 2045-2060]$ G-Physics and T-Physics
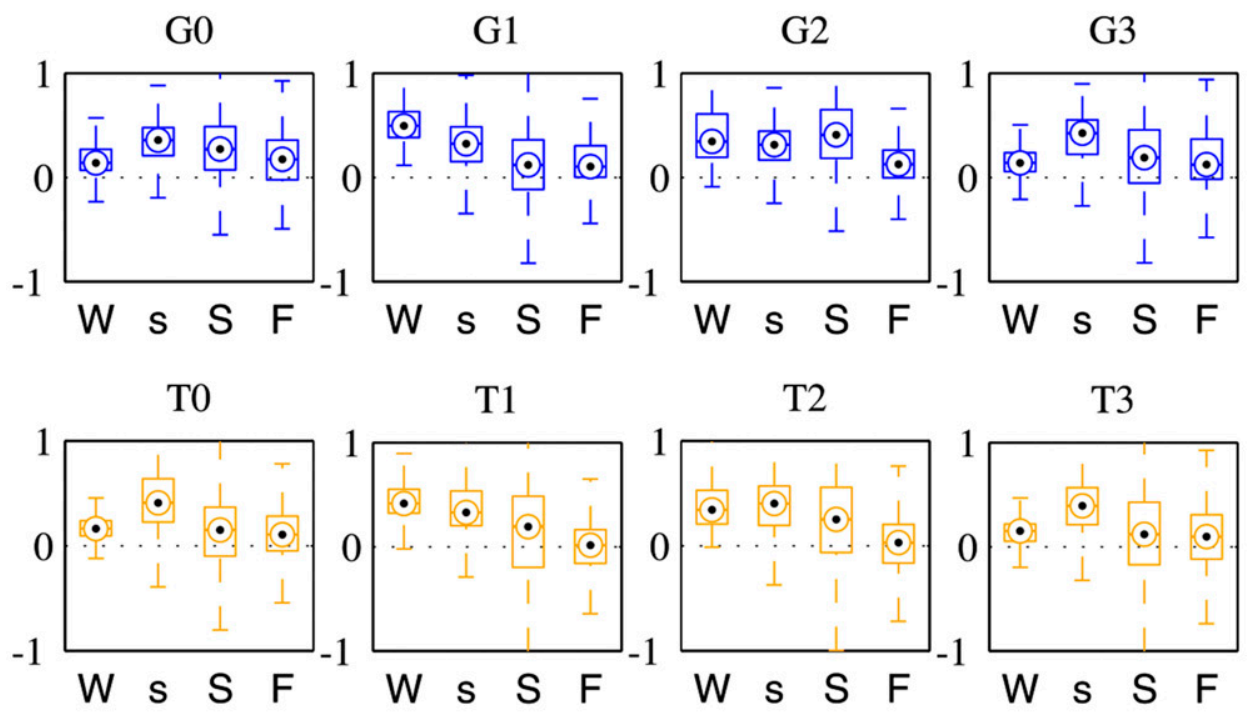

b) $[\mathrm{C} 0 / 2045-2060],[\mathrm{C} 0-$ SeaIce/2045-2060] and [C0/2085-2100]
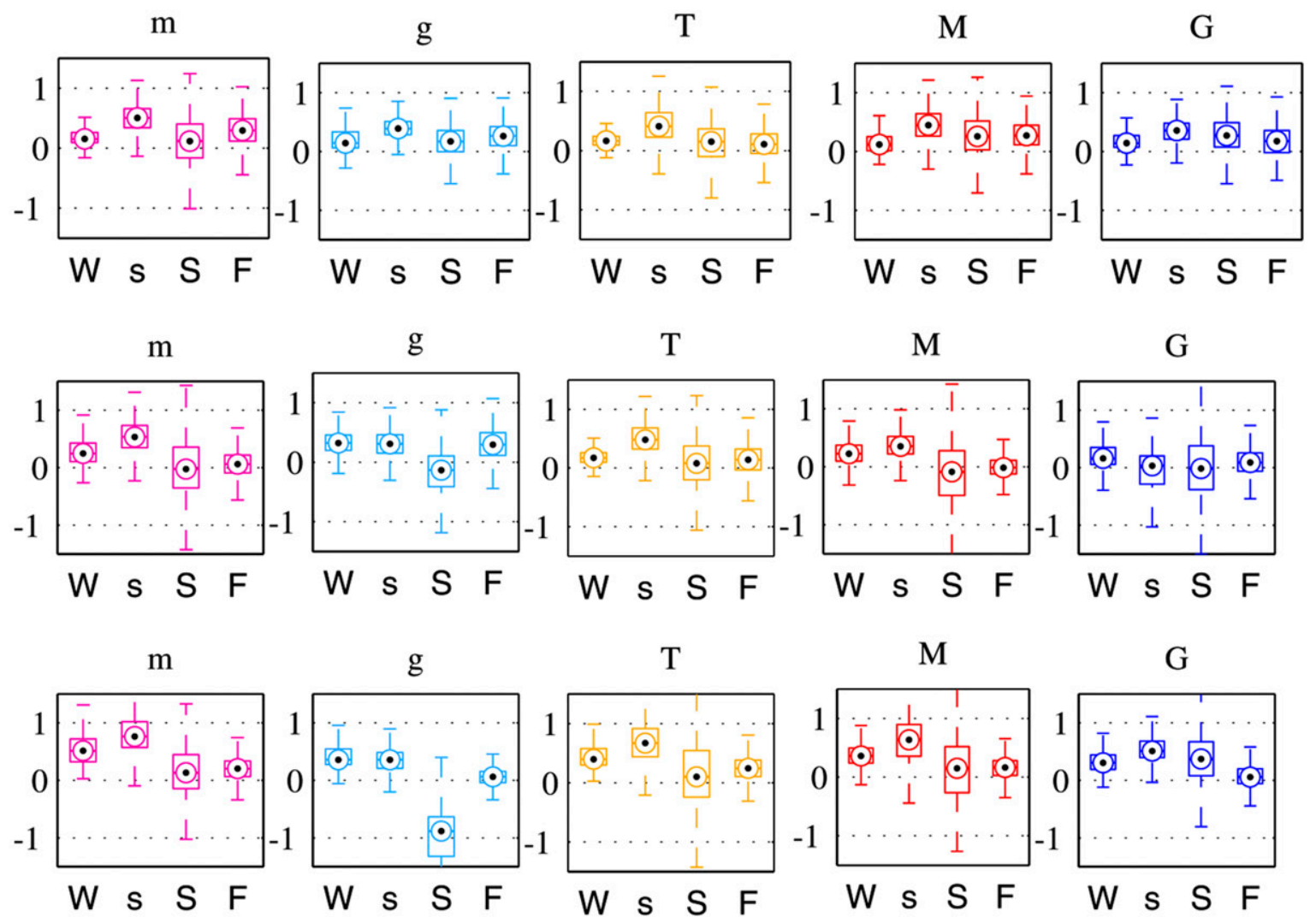

FIG. 10. Box-and-whisker plots for the Great Lakes region (inner domain) of the projected changes of total precipitation (mm day ${ }^{-1}$ ) in seasonal (3 month) averages: DJF (W), MAM (s), JJA (S), and SON (F). For each experiment (a) of the two IC ensembles with G and T physics configurations and (b) of the three physics ensembles with future experiments (top) $\mathrm{C} 0$ midcentury, (middle) C0-SeaIce midcentury, and (bottom) $\mathrm{C} 0$ end of the century and all physics configurations: (left)-(right) m, g, T, M, and G. 
a) $[\mathrm{C} 0+\mathrm{C} 1+\mathrm{C} 2+\mathrm{C} 3 / 2045-2060]$ G-Physics and T-Physics
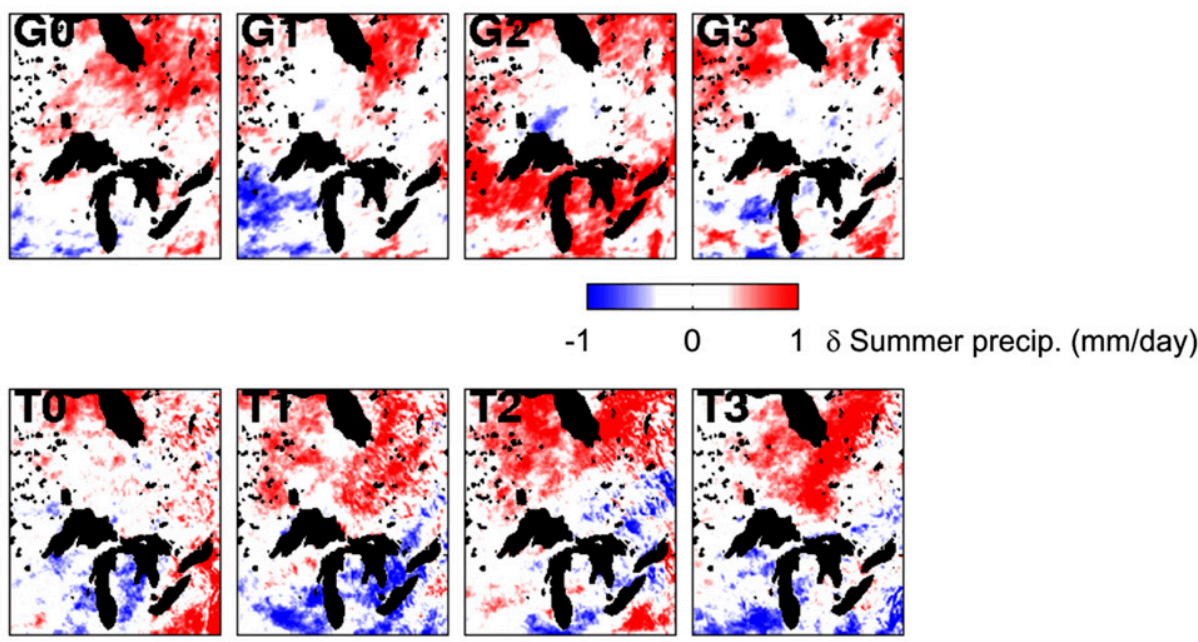

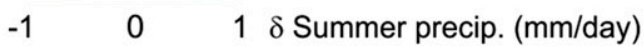

b) $[\mathrm{C} 0 / 2045-2060],[\mathrm{C} 0-$ SeaIce/2045-2060] and [C0/2085-2100]
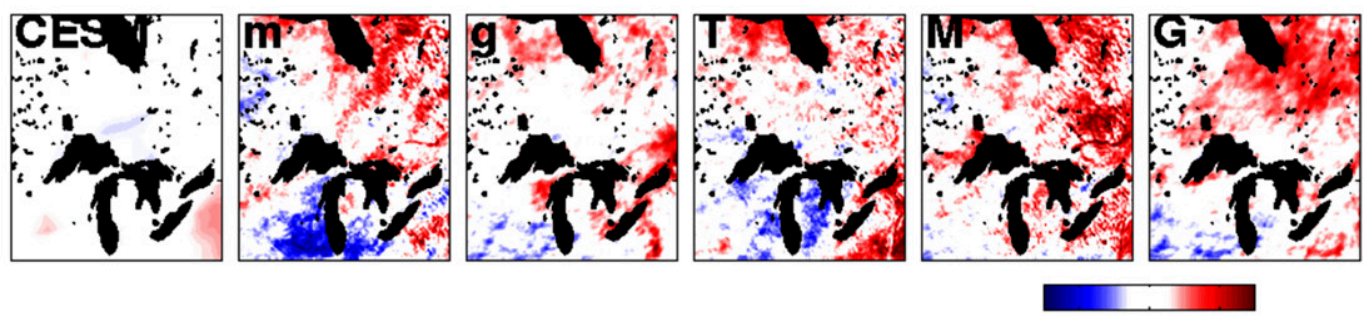

$\delta$ Summer precip. (mm/day) $-1 \quad 0 \quad 1$
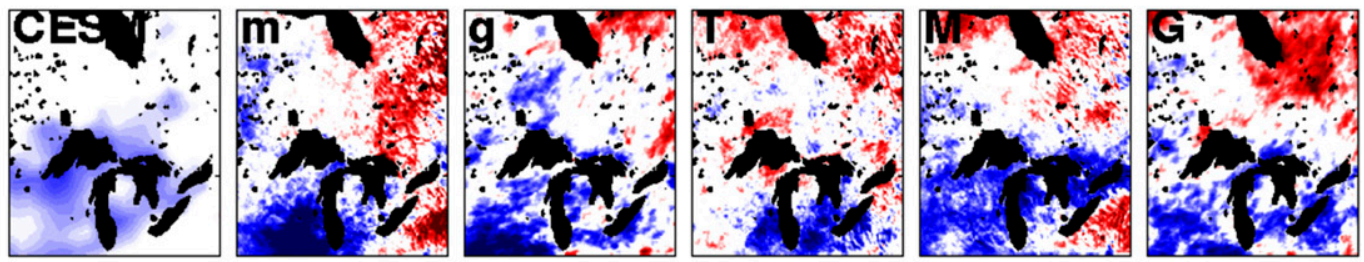

$\delta$ Summer precip. (mm/day) $-1 \quad 0 \quad 1$
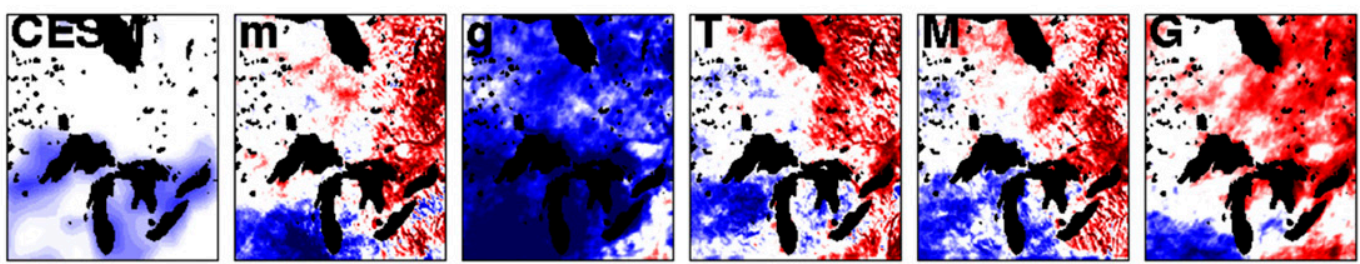

$\delta$ Summer precip. (mm/day) $-1 \quad 0 \quad 1$

FIG. 11. Future summer precipitation change $\left(\mathrm{JJA} ; \mathrm{mm} \mathrm{day}^{-1}\right)$ for each experiment (a) of the two IC ensembles with $\mathrm{G}$ and $\mathrm{T}$ physics configurations and (b) of the three physics $\mathrm{C} 0$ end of the century and for CESM1 simulation and all physics configurations: (left)-(right) CESM1, m, g, T, M, and G. 
severe summer decrease is obviously the explanation for the unexpectedly small annual and small heavy rainfall increase described in the previous section for that specific simulation.

The summer future precipitation change for all projections is shown in Fig. 11. There is an evidently large spatial variability in the local trends with, for instance, patches of decreased precipitation projected to be surrounded by large areas of increase in precipitation (or vice versa). This variability in local trend within the domain and between different simulations is inherently due to a combination of the internal variability within the regional climate model and to the difference in physics parameterizations employed for each simulation. When comparing the two IC ensembles (Fig. 11a), the summer spatial variations are different for the two physics configurations but for the same CESM1 simulation, implying that they are generated internally in the WRF domains, whereas the winter spatial pattern of future precipitation change appears to be strongly dependent on the CESM1 simulation and largely independent of the WRF physics configurations (Fig. S5a in the supplemental material). Furthermore, in the three physics ensembles for different time horizons (Fig. 10b), it is important to note the difference in the spatial scale of the variability between the very small spatial-scale variability seen in the simulations with the Kain-Fritsch cumulus scheme (m, T, and M) and the smoother spatial variability of the simulations with the Grell-3 cumulus scheme ( $\mathrm{g}$ and $\mathrm{G})$. This is likely because the latter is an ensemble scheme, which leads to less systematic triggering and thus a smoother and more natural pattern. Such a large spatial variability in the local climate change signal is the primary reason for presenting, up to this point, the results as box plots of the spatial distributions of the signals.

However, despite this small-scale variability, regional variations within the inner domain are evident and constitute a climate change signal independent of the internal variability. Concentrating first on the midcentury reduced sea ice scenario (Fig. 11b, middle), the southwestern region of the inner domain (Wisconsin and Minnesota) has a consistent decrease in summer precipitation among all physics configurations. For several of the simulations, this region of summer precipitation decrease will be seen as extending almost to the southeastern corner and/or to the northwestern corner of the domain. In contrast, the northeastern corner of the domain is characterized by a consistent increase in summer precipitation for all simulations of the midcentury reduced sea ice scenario, with the increase in summer precipitation spreading to the southeastern and/or northwestern corners of the domain depending on the simulation. This spatial divide in the reduced sea ice scenario between the southwestern and northeastern region constitutes a robust regional climate change as it is also clearly present in all other projections: muted in the other midcentury projections and stronger in the end-of-the-century projections (Fig. 11b, top and bottom, respectively). The only exception is of course the physics configuration $\mathrm{g}$ at the end of the century, which projects drying everywhere. The fact that the future decrease of summer precipitation in the southwestern corner of the inner domain is a robust feature across most of the members of the IC and physics ensembles demonstrates that it appears to arise because of a consistent change in the large-scale atmospheric transport of moisture. This decrease is indeed part of a larger region of summer precipitation decrease over the central and northwestern parts of the United States, particularly in the midcentury reduced sea ice scenario and for the end of the century, for which it is independent of the physics configuration (Fig. S6 in the supplemental material). In fact, this region of large-scale summer precipitation decrease over the United States is already present in the global CESM1 simulation (Fig. S6) with a decrease around the Great Lakes, which is somewhat muted compared to the WRF highresolution results (Fig. 11). Furthermore, this pattern is consistent with the summer precipitation changes seen in the CMIP3 and CMIP5 ensembles, as reported in the Fifth Assessment Report of the IPCC (IPCC 2013, chapter 14); most GCMs project an increase of summer precipitation in the northern part of the continent and along its east coast, while a decrease is typically projected for the south and Midwest, with the Great Lakes located in the region of transition [see also Kutzbach et al. (2005) and Erler and Peltier (2017) for further discussion of this phenomenon].

Inspection of the July moisture fluxes into the North American WRF outer domain from the land and ocean surface evaporation and from the water vapor advection derived from the boundary conditions provided by the global CESM1 simulations provides only a modest basis upon which to understand the continental-scale evaporation patterns shown in Fig. 12. There are many features common to the evaporation anomalies characteristic of the three future projections that can influence the precipitation over the continent. First, the increase of moisture advection by the midlatitude westerlies entering from the northwestern corner of the domain, coupled with an increase in North Pacific surface evaporation (not shown), is likely related to the increase in precipitation in the northern part of the continent. Second, the increase of moisture advection by the tropical easterlies entering from the southeastern corner of the domain, coupled to an 


\section{a) configuration g July evaporation and evaporation changes ( $\mathrm{mm} /$ day) C0 1979-1994 C0 2045-2060 C0-SI 2045-2060 C0 2085-2100}
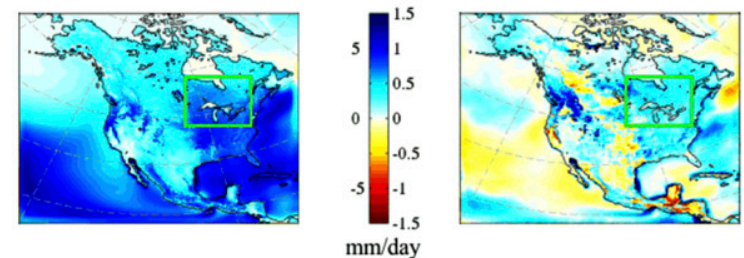

$\mathrm{mm} /$ day
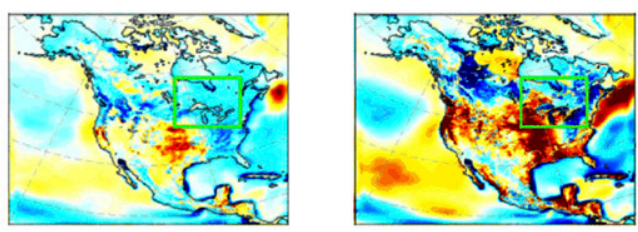

\section{b) configuration}
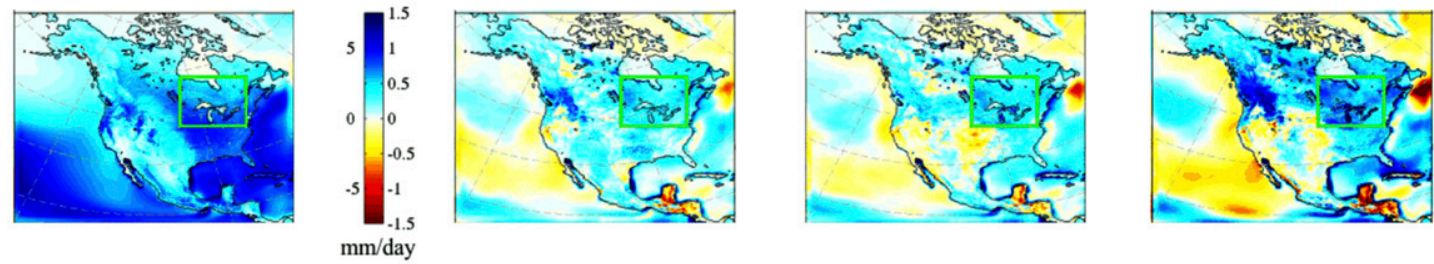

c) configuration
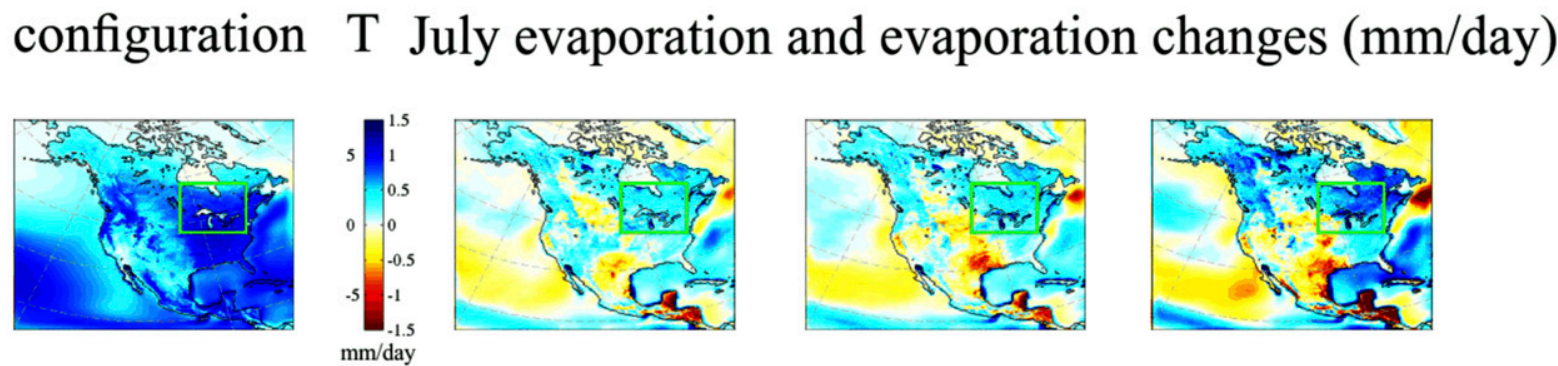

$\mathrm{mm} /$ day

FIG. 12. Historical and future change in surface evaporation $\left(\mathrm{mm} \mathrm{day}^{-1}\right)$ for the month of July of configurations g, G, and T. Note that the color scale for (left) the mean of the historical period (scale to the left of the color bar) is 5 times larger than for (three right columns) the future anomalies (scale to the right of the vertical color bar).

increase of surface evaporation in the subtropical Atlantic Ocean and the Gulf of Mexico (not shown), is likely related to the increase in precipitation along the eastern coast of the continent. Finally, there is a decrease in surface evaporation from the (sub)tropical Pacific and from parts of the southwestern United States, which is likely related to the large-scale decrease in summer precipitation over the Midwest described previously.

Because up to $50 \%$ of the total precipitation over the northeastern part of the continent originates upstream from rain recycling (Van der Ent et al. 2010), it seems natural to assume a direct relation between the decrease in surface evaporation from the southwestern and central United States and the decrease in precipitation over the central and northeastern parts of the United States. This relation is even more likely when considering the projection at the end of the century with the physics configuration g. In that case it is evident that both decreases are drastic and dramatically different from the same projections with the other physics ensemble members, and it appears likely that both drastic decreases in configuration $\mathrm{g}$ are related. The fact that precipitation is limited by a lack of moisture availability and a significantly larger surface temperature increase resulting from a lack of surface evaporation over land explains at the same time why the Clausius-Clapeyron relation did not hold for the configuration of that specific projection.

The dramatic reduction of surface evaporation from the southwestern United States to the Canadian border and to the central United States in physics configuration $\mathrm{g}$ is directly related to very dry soil in those regions in the summer. In fact, configuration g compared to the four other physics configurations is particularly prone to drought conditions in that region for two primary reasons: first, the Grell-3 cumulus scheme was shown to have overly weak summer precipitation in the southern United States (cf. configurations $\mathrm{g}$ and $\mathrm{G}$ to $\mathrm{m}$ and $\mathrm{M}$, respectively, in Fig. 4), and second, the Noah MP land surface model that is employed in configuration $g$ tends 

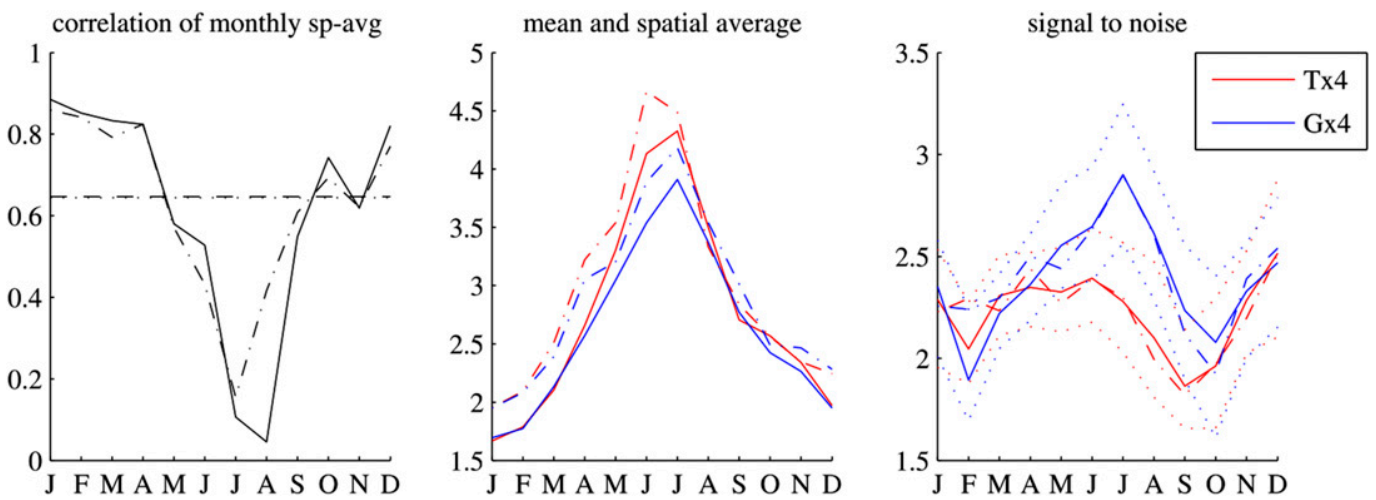

FIG. 13. Comparison of the interannual variability of the monthly averaged precipitation in the inner domain between historical ensembles $\mathrm{Gx} 4$ and $\mathrm{Tx} 4$. (left) Correlation between spatially averaged monthly ts indices of $\mathrm{Gx} 4$ and $\mathrm{Tx} 4$ for each month separately (solid line). The horizontal dashed-dotted line corresponds to the value of the correlation coefficient between the complete monthly ts indices. (center) Monthly averaged ts indices in Gx4 (blue solid line) and Tx4 (red solid line) historical ensembles. (right) Monthly plot of the ratio of monthly standard deviation to its monthly average [Tx4 (blue) and Gx4 (red)]. Shown are the median (solid line) and the 25th- and 75th-percentile (dotted lines) values for the inner domain. Dashed-dotted lines in each panel correspond to the midcentury future ensembles for comparison.

to have drier soils than the original Noah LSM in all simulations (configurations $\mathrm{g}$ and $\mathrm{m}$ have a North American vertically averaged soil moisture 19\% lower than configurations $\mathrm{G}$ and $\mathrm{M}$, respectively).

However, all WRF physics configurations, as well as the driving CESM1 simulations, are characterized by a future diminution of summer precipitation over the central United States and near the Great Lakes (Figs. 11 and S6). Because these summer diminutions of both evaporation and precipitation are larger for increasingly warm climate change independently of the physics configuration, it seems plausible that the causal relationship between both holds true in all simulations. If this is the case, then the relationship described here for multiyear averages should also be true for the interannual variability of evaporation and precipitation, a preliminary analysis of which is presented in the next section.

\section{c. Interannual variability of summer precipitation}

The interannual variability of precipitation in the Great Lakes region is first analyzed in the IC ensemble comprised of all 15-yr historical downscaling experiments driven by CESM1 simulations $\mathrm{CO}, \mathrm{C} 1, \mathrm{C} 2$, and $\mathrm{C} 3$ (1979-94; see Table 2), for configurations G and T. For this analysis all four simulations of one physics configuration are concatenated together to create two equivalent 60 -yr simulations, which will be referred to as $\mathrm{Gx} 4$ and Tx4. Having two ensembles of the same CESM1 simulations but downscaled with two different physics configurations will allow us to distinguish between the interannual variability driven by the large-scale circulation of the GCM and the internally produced variability of the RCM (whether or not due to different physics).

Monthly precipitation averages over the entire inner domain are used to construct an interannual index (ts). The correlation between the two 720-month indices of $\mathrm{Gx} 4$ and $\mathrm{Tx} 4$ ensembles is 0.66 , indicating a rather large influence of the global-scale GCM on the interannual variability of precipitation over the Great Lakes region. However, when this correlation is broken down month by month (Fig. 13), it is evident that the interannual variability of the GCM is the primary driver of the precipitation variability in the Great Lakes only during the colder seasons (with a maximum correlation of 0.89 for January), whereas its influence is much reduced during the warmer months and disappears entirely in the summer (without statistically significant correlations for July and August). Note that the same results are obtained when considering the four midcentury simulations (2045-60) instead of the historical simulations (1979-94). These seasonal results can be attributed to the fact that, on one hand, the stronger large-scale circulation in winter can maintain the same large-scale precipitation patterns over North America in the different physics configurations and that, on the other hand, a substantial part of the summer precipitation over North America (and the Great Lakes region in particular) is driven by local convective processes that are much more prone to trigger internal variability within the RCM.

To analyze the interannual variability of summer precipitation, the surface evaporation, the total precipitation, the difference between evaporation and precipitation $(E-P)$, and the diagnosed advection of 
a) ensemble $\mathrm{Gx} 4$

- Evaporation
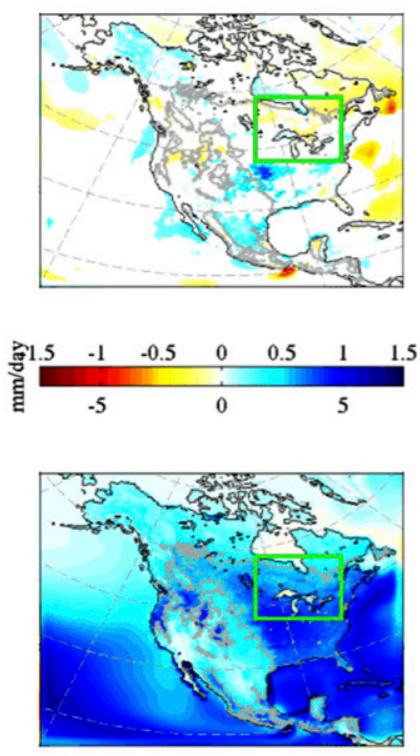

b) ensemble $\mathrm{Tx} 4$
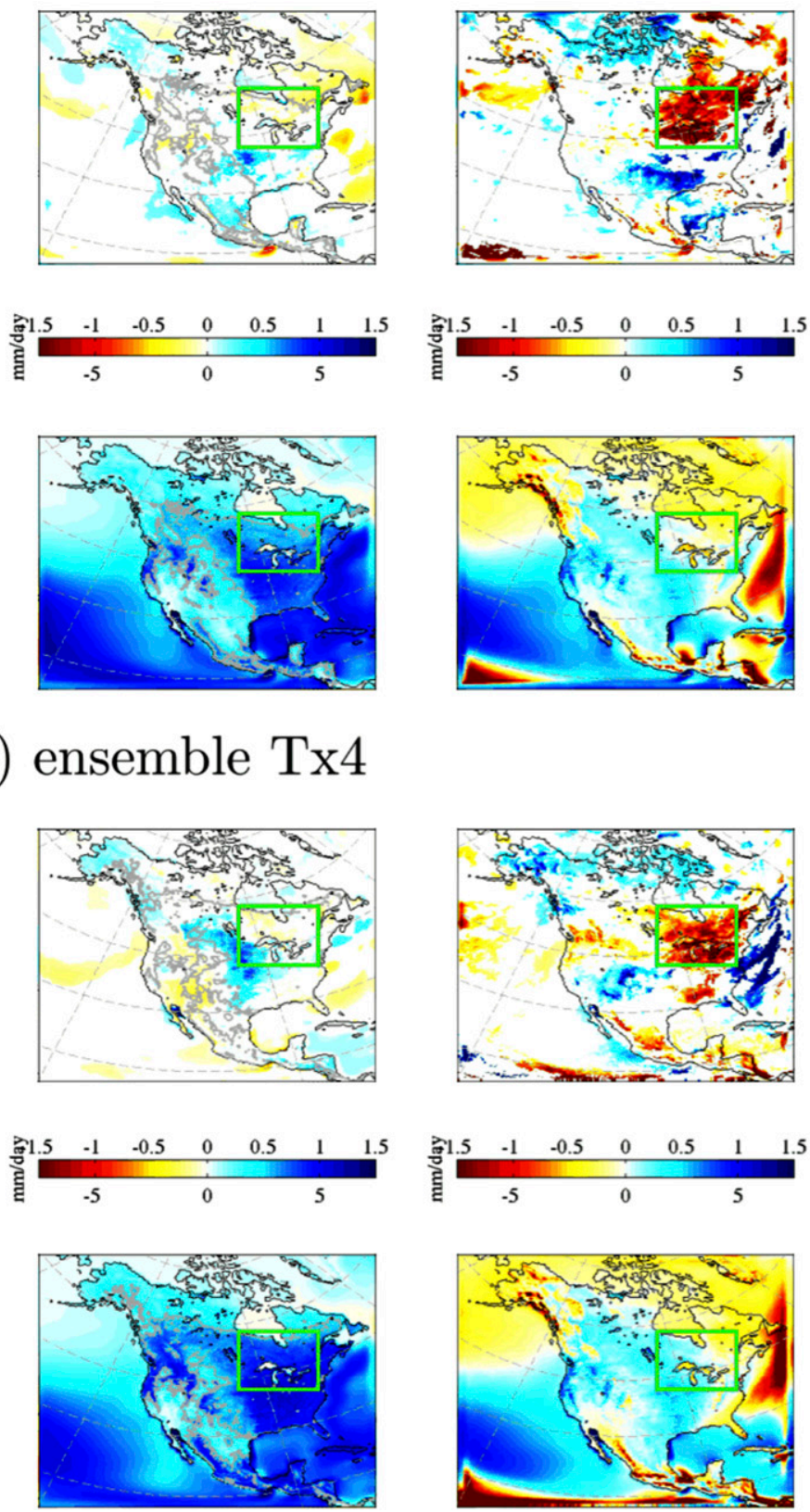

\section{Precipitation}
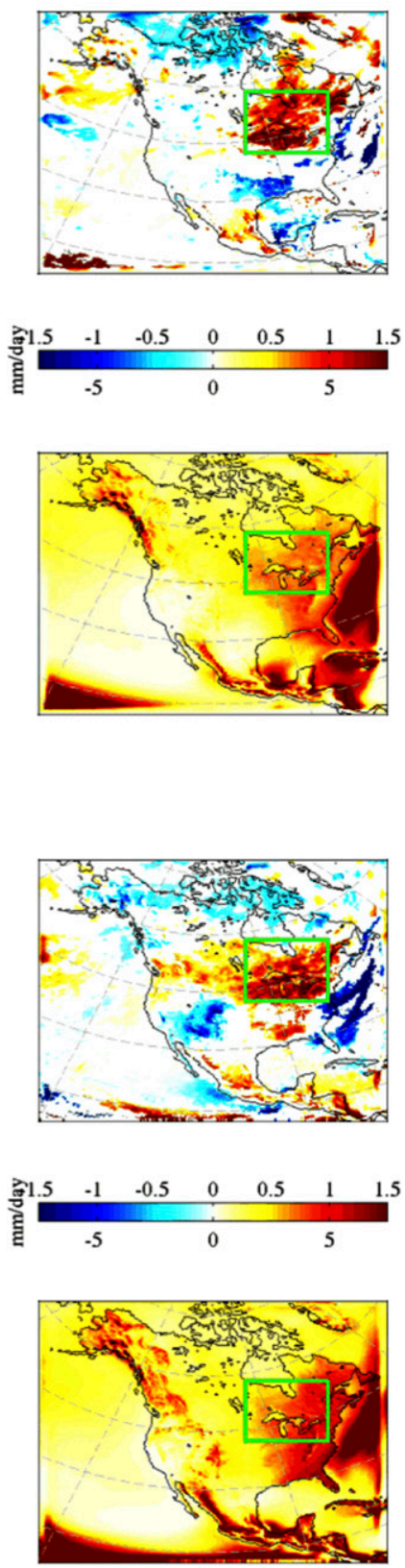

FIG. 14. Regression of evaporation, evaporation minus precipitation, and precipitation $\left(\mathrm{mm} \mathrm{day}^{-1}\right)$ onto the spatially averaged ts7 are shown in the top rows for the innermost domain of ensembles (a) Gx4 and (b) Tx4. Regression values are plotted only if they are statistically significant at the $90 \%$ level. The July-averaged fields over the continent are shown in the bottom rows of (a) and (b). The color scale for the mean is 5 times larger than for the regressions. Note that the color scale is reversed for precipitation.

water vapor across the lateral boundaries of the North American domain (not shown) are regressed against the interannual index of precipitation for July (ts7) over the Great Lakes region for both $\mathrm{Gx} 4$ and $\mathrm{Tx} 4$ historical ensembles (Fig. 14). Comparing first the regressions of precipitation onto ts7 (Fig. 14, right) shows that the precipitation variability in the inner domain is associated with opposite variability in the region to the south 


\section{C0 1979-1994 C0 2045-2060 C0-SI 2045-2060 C0 2085-2100}
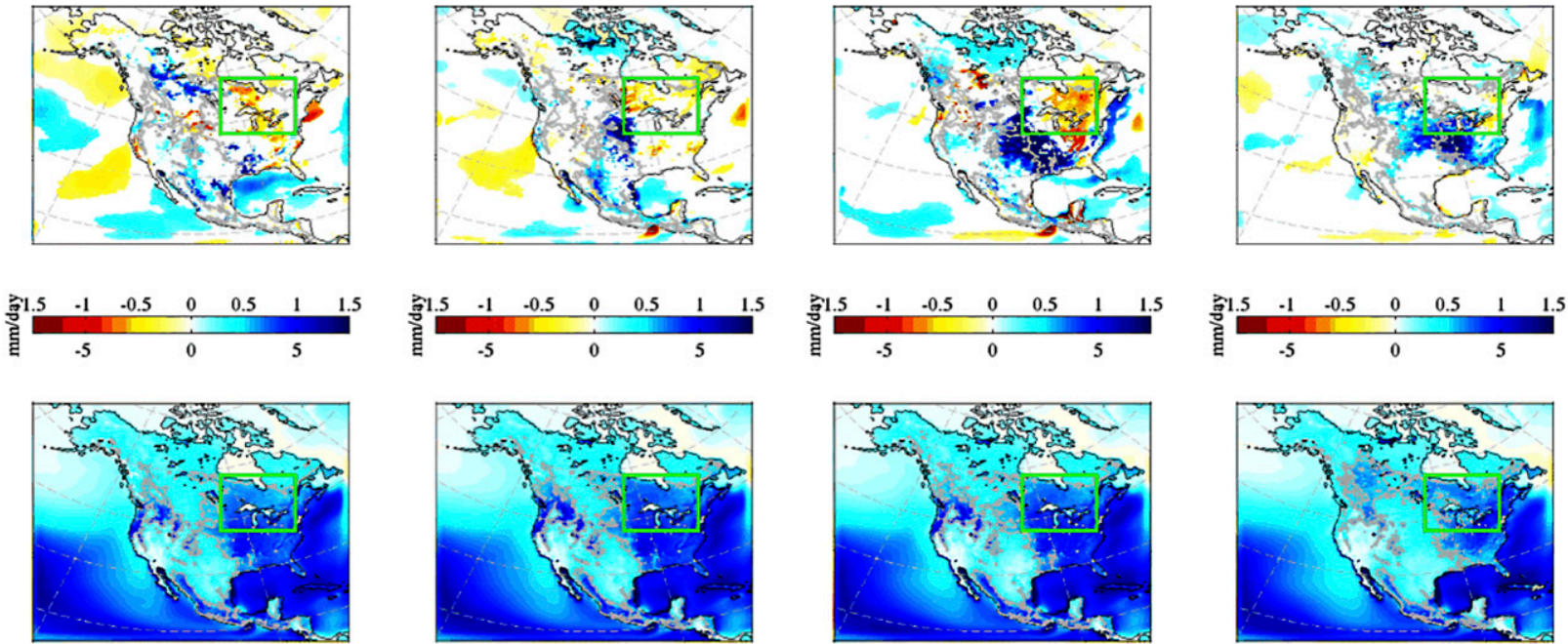

FIG. 15. (top) Regression of evaporation onto the spatially averaged ts7 in the inner domain of configuration $\mathrm{g}$ for the following experiments: (left)-(right) C0 historical, $\mathrm{C} 0$ midcentury, $\mathrm{C} 0$-SeaIce midcentury, and $\mathrm{C} 0$ end of the century. Regression values are plotted only if they are statistically significant at the $90 \%$ level. (bottom) July-averaged fields over the continent are shown, and the color scale for the mean is 5 times larger than for the regressions.

of the inner domain in ensemble $\mathrm{Gx} 4$ and in the region to the southwest of the inner domain in ensemble Tx4. These differences tend to imply different changes in the regional circulation associated with Great Lakes precipitation variability, which is to be expected since the mean July precipitation for the two physics configurations are significantly different. Considering next the regressions on $E-P$ (Fig. 14, center) reveals almost exactly the same patterns as the regression on precipitation alone, indicating that the interannual variability of the surface water budget in July is driven primarily by precipitation despite the dominance of mean evaporation over mean precipitation for the majority of North America in July.

The regression of evaporation alone onto ts7 (Fig. 14, left) is fairly weak everywhere in the North American domain except for a region southwest of the inner domain. Although the area covered by that region is different in $\mathrm{Gx} 4$ and $\mathrm{Tx} 4$, it is located (i) upwind from the inner domain and (ii) at the border of the dry southwestern U.S. (Great Plains) region (the dry southwestern United States is apparent in the mean July fields as a region of low evaporation, e.g., weaker than $2 \mathrm{~mm}$ day $^{-1}$ ). The regression of evaporation onto ts 7 therefore highlights the fact that precipitation in the Great Lakes region is strongly related to the interannual variability of the spatial expansion (or contraction) of the dry region in the southwestern United States. More specifically, when the dry region in the southwestern United States is relatively weak, rain recycling can occur upwind of the
Great Lakes and lead to larger precipitation in the Great Lakes region. In contrast, when the dry region in the southwestern United States extends farther eastward and northward, rain recycling does not occur as efficiently upwind of the Great Lakes region, which therefore receives less precipitation. It is important to note that the regressions of the advection of water vapor across the boundary of the North American domain onto ts7 (not shown) differ between the $\mathrm{Gx} 4$ and $\mathrm{Tx} 4$ ensembles. Although one common aspect of these regressions is a positive advective flux of moisture around $40^{\circ} \mathrm{N}$ in the Pacific region, which could be expected to increase precipitation over the latitudinal band of the Great Lakes region (Fig. 13), this positive advective flux is not a good predictor of enhanced precipitation over the Great Lakes region because the same large-scale circulation boundary forcing has been shown to drive uncorrelated interannual variability of July precipitation over the Great Lakes region in $\mathrm{Gx} 4$ and $\mathrm{Tx} 4$ (Fig. 13). Moreover, in all the other historical or future simulations for which the same regression has been performed (Figs. 15 and S7 in the supplemental material), this positive advective flux around $40^{\circ} \mathrm{N}$ is sometimes present, sometimes absent, or even replaced by a negative flux. This is in sharp contrast to the positive evaporative flux present in all regressions upwind from the Great Lakes (Figs. 14, 15, and S7), which highlight the summer relationship between the expansion or contraction of the dry region in the southwestern and central United States and the precipitation in the Great 
Lakes region. It is therefore concluded that, in summer, the variability of the advective flux of moisture around $40^{\circ} \mathrm{N}$ in the Pacific is not a primary driver of the Great Lakes precipitation variability.

In all physics configurations, the averaged summer dry region of the southwestern United States is expanding eastward and northward with increasingly warm climate (see, e.g., the mean July evaporation of configuration $g$ in Fig. 15). This continental expansion is part of the general expansion of the dry subtropical region under future warming, which has been shown to be a robust feature of climate change among all GCM projections (e.g., see Scheff and Frierson 2012). A consequence of this expansion is an increased dependence of Great Lakes precipitation on the evaporation over the southwestern and central United States: with increasingly warm climate, the regression of surface evaporation onto the inner domain precipitation indices displays an unequivocal increase of the amplitude and spatial extent of the patterns of relationship across all $\mathrm{C} 0$ experiments (as shown for configuration g; Fig. 15). Although the statistical significance of such a result for simulations of only 15-yr duration cannot be as robust as for the 60 -yr ensemble used previously, the fact that all physics configurations show the same increase of the amplitude and spatial extent of the patterns of relationship (e.g., for configuration G; Fig. S7) provides confidence in the credibility of this result. Moreover there exists a relatively simple mechanism to explain it: as the regions upwind of the Great Lakes become drier on average under increasingly warm climate, the occurrences of yearly neardrought conditions increases, as well as the occurrence of soil moisture limitations for rain recycling which therefore impacts more efficiently the interannual variability of precipitation over the Great Lakes basin region. This is one of the most important results of the analyses presented in this paper. Further analysis of what appears to be a continental-scale soil moisture mediated teleconnection will be the subject of additional future analyses.

\section{Summary and discussion}

An initial physics-based miniensemble of WRF-based dynamical downscaling analyses of climate change projections for the Great Lakes basin (d'Orgeville et al. 2014) has been considerably expanded to include a multiplicity of ensembles based upon a variety of methodological assumptions. The goal of this work has been to investigate future precipitation uncertainty in the Great Lakes basin region arising from the natural variability of climate captured in multiple CESM1 simulations produced on the basis of different assumed initial conditions and extended further into the future to the end of the present century.
This significant expansion of the previously published physics-based ensemble analyses of d'Orgeville et al. (2014) has confirmed the robustness of two of the four original findings, namely that, independently of the physics configuration, time horizon, and initial conditions employed in the parent GCMs, 1) the total precipitation will increase in the future and 2) the projected increase in heavy rainfall will be larger or equal to the Clausius-Clapeyron reference value of $7 \%$ increase per degree Celsius of surface warming.

The two additional original findings of d'Orgeville et al. (2014) are also confirmed, but with caveats. First, it has been demonstrated that, by the end of the century, there is a significant fattening of the tail of the daily rainfall distribution. However, this fattening can be obscured by natural variability under the moderate warming of midcentury on the basis of which this result had been originally concluded. Second, the increase in average rainfall intensity was confirmed to be close to the $\mathrm{CC}$ reference of $7 \%{ }^{\circ} \mathrm{C}^{-1}$ of surface warming, but herein for only the midcentury ensembles. The end-ofthe-century ensembles, corresponding to larger global warming projections, were characterized by an average rainfall intensity increase of only $5.5 \%{ }^{\circ} \mathrm{C}^{-1}$ of surface warming. The difference with the Clausius-Clapeyron reference value indicates that some lack of moisture can restrict the expected thermodynamic increase of average precipitation in the Great Lakes region insofar as its dependence upon surface temperature is concerned. This potential moisture restriction under strong global warming has been dramatically illustrated in one outlier simulation for the end-of-the-century projection, for which even the heavy rainfall increase is affected.

In this $\mathrm{g}$ configuration outlier, summer rainfall is drastically reduced as a result of a large persistent drought occurring in the central and western United States that extends to the northeast to the Great Lakes basin region of Canada and the United States. These dry conditions prevent the efficient recycling of rain over the center of the continent, therefore restricting the increase in moisture availability and preventing the increase in summer rainfall over the Great Lakes region that would be inferred to occur based upon the increase in surface temperature and its potential thermodynamic increase of moisture alone. However, it is primarily the light rainfall events that are reduced by the rain-recycling restriction, whereas extreme summer rainfall is still expected to increase in the future according to this extreme scenario, most probably because the moisture that supports the occurrence of these extreme events is derived primarily from the Gulf of Mexico to the south. Further detailed analyses of this scenario are planned but are outside the scope of the present paper. 
This dramatic summer rainfall reduction over the Great Lakes basin occurs in only one ensemble member at the end of the century. This member of the physics ensemble employs the Grell-3 cumulous scheme and the Noah-MP land surface scheme, both of which tend to produce a somewhat drier climate in WRF version 3.4. It is possible that this propensity toward dryness, combined with the impact of anthropogenic global warming, and likely a large contribution from natural variability, resulted in the large-scale drought that characterizes end-of-the-century climate in this ensemble member. However, further simulations with different initial and boundary conditions, land surface models, and/or different regional and global climate models will need to be employed to expand the current physics based ensembles to more fully investigate the actual likelihood of future large-scale summer drought over the North American continent such as that described in the most dramatic of our projections of end-of-the-century climate conditions. Our expectation, to be confirmed by the further analyses we are planning, is that the driest of our end-of-the-century projections will prove to be unphysical.

Independently of the plausibility of this outlier, all simulations presented here display a sensitivity of summer rainfall over the Great Lakes region to the impact upon rain recycling that is projected to occur southwest of this region. Unlike winter precipitation, it was shown in the historical simulations that the interannual variability of summer precipitation is not driven by the changes in the large-scale atmospheric circulation and SST forcing from the GCM parent model simulations, but is instead dependent on the evaporation-driven rain recycling from the central United States, which is a strong function of the RCM physics employed. More importantly, for all of the physics configurations analyzed, this dependence becomes stronger for increasingly warmer climates as a consequence of the expansion eastward and northward of the droughtprone region in the southwestern United States; the drier the region southwest of the Great Lakes becomes, the more strongly land surface evaporation in the region is restricted, which therefore affects more significantly the precipitation in the Great Lakes region. Reasons for this expansion are obviously related to the general northward expansion of the dry subtropical regions, which is a robust feature of future climate change projections. Although detailed discussions of the mechanisms responsible for the general northward expansion of the dry subtropical regions (see, e.g., Scheff and Frierson 2012) is beyond the scope of this paper, any theory of the process should be noted by the fact that such expansion is well modeled at the continent scale by the physics employed in the RCM we have been using for the present analyses.

Finally, because the CC scaling was a good predictor of the change in rainfall intensity, most of our analysis was based upon the change in the source of moisture following a conventional water budget approach. On the one hand, this approach is particularly suitable when considering that up to $50 \%$ of the total precipitation over the northeastern part of the continent originates upstream from rain recycling (van der Ent et al. 2010). On the other hand, it has been suggested that regional variation of local changes in the horizontal energy transport can also help to explain local precipitation changes (Muller and O'Gorman 2011). While this energetic approach requires a global framework, which cannot be simply applied to RCM simulations, there are nevertheless numerous signs in our present analysis that changes in the large-scale atmospheric circulation might also be involved in the average precipitation changes. Changes in the energetics cannot be ruled out as playing a role in the rainfall precipitation changes described here and, in fact, could be a candidate when trying to explain why the CC scaling is a good predictor for the changes in rainfall intensity but not for average precipitation.

Acknowledgments. The simulations discussed in this paper were performed in part on the SciNet High Performance Computing facility of the University of Toronto, which is a component of the Compute Canada HPC platform. Analyses also made significant use of the SOSCIP Blue Gene/Q system that is also operated by SciNet. The research at the University of Toronto on the dynamical downscaling of climate change projections over the Great Lakes basin and the Province of Ontario is supported by the Ontario Ministry of Environment and Climate Change. The research of WRP at Toronto is also supported by NSERC Discovery Grant A9627. (The CRU TS3.10 and NARR observational datasets employed in this study are publicly available online at http://www.cru.uea.ac.uk/cru/ data/hrg/ and http://www.esrl.noaa.gov/psd/data/gridded/ data.narr.htm, respectively.)

\section{REFERENCES}

Allen, M. R., and W. J. Ingram, 2002: Constraints on future changes in climate and the hydrologic cycle. Nature, 419, 224-232, https://doi.org/10.1038/nature01092.

Bates, G. T., F. Giorgi, and S. W. Hostetler, 1993: Toward the simulation of the effects of the Great Lakes on regional climate. Mon. Wea. Rev., 121, 1373-1387, https://doi.org/10.1175/ 1520-0493(1993)121<1373:TTSOTE > 2.0.CO;2.

Chen, F., and J. Dudhia, 2001: Coupling an advanced land surfacehydrology model with the Penn State-NCAR MM5 modeling system. Part I: Model implementation and sensitivity. 
Mon. Wea. Rev., 129, 569-585, https://doi.org/10.1175/ 1520-0493(2001)129<0569:CAALSH>2.0.CO;2.

Cox, H. J., 1917: Influence of the Great Lakes upon movement of high and low pressure areas. Proc. Second Pan-American Scientific Congress, Vol. 2, Washington, DC, 432-459.

Davies, H., and R. E. Turner, 1977: Updating prediction models by dynamical relaxation: An examination of the technique. Quart. J. Roy. Meteor. Soc., 103, 225-245, https://doi.org/ 10.1002/qj.49710343602.

d'Orgeville, M., W. R. Peltier, A. R. Erler, and J. Gula, 2014: Climate change impacts on Great Lakes basin precipitation extremes. J. Geophys. Res. Atmos., 119, 10 799-10 812, https:// doi.org/10.1002/2014JD021855.

Emori, S., and S. J. Brown, 2005: Dynamic and thermodynamic changes in mean and extreme precipitation under changed climate. Geophys. Res. Lett., 32, L17706, https://doi.org/ 10.1029/2005GL023272.

Erler, A. R., 2015: High resolution hydro-climatological projections for western Canada. Ph.D thesis, Department of Physics, University of Toronto, $215 \mathrm{pp}$.

- , and W. R. Peltier, 2016: Projected changes in precipitation extremes for western Canada based upon high-resolution regional climate simulations. J. Climate, 29, 8841-8863, https:// doi.org/10.1175/JCLI-D-15-0530.1.

— river basins at the Canadian west coast based upon highresolution regional climate simulations. J. Climate, 30, 80818105, https://doi.org/10.1175/JCLI-D-16-0870.1.

$\longrightarrow,-$, and M. d'Orgeville, 2015: Dynamically downscaled high resolution hydroclimate projections for western Canada. J. Climate, 28, 423-450, https://doi.org/10.1175/JCLI-D-14-00174.1.

Gent, P. R., and Coauthors, 2011: The Community Climate System Model version 4. J. Climate, 24, 4973-4991, https://doi.org/ 10.1175/2011JCLI4083.1.

Grell, G. A., and D. Dévényi, 2002: A generalized approach to parameterizing convection combining ensemble and data assimilation techniques. Geophys. Res. Lett., 29, 1693, https:// doi.org/10.1029/2002GL015311.

Gula, J., and W. R. Peltier, 2012: Dynamical downscaling over the Great Lakes basin of North America using the WRF regional climate model: The impact of the Great Lakes system on regional greenhouse warming. J. Climate, 25, 7723-7742, https:// doi.org/10.1175/JCLI-D-11-00388.1.

Harris, I., P. Jones, T. Osborn, and D. Lister, 2014: Updated highresolution grids of monthly climatic observations-The CRU TS3.10 dataset. Int. J. Climatol., 34, 623-642, https://doi.org/ 10.1002/joc. 3711 .

Hawkins, E., and R. Sutton, 2009: The potential to narrow uncertainty in regional climate predictions. Bull. Amer. Meteor. Soc., 90, 1095-1107, https://doi.org/10.1175/2009BAMS2607.1.

Held, I. M., and B. J. Soden, 2006: Robust responses of the hydrological cycle to global warming. J. Climate, 19, 5686-5699, https://doi.org/10.1175/JCLI3990.1.

Hong, S.-Y., and J.-O. J. Lim, 2006: The WRF single-moment 6class microphysics scheme (WSM6). J. Korean Meteor. Soc, $\mathbf{4 2}$, 129-151.

Iacono, M. J., J. S. Delamere, E. J. Mlawer, M. W. Shephard, S. A. Clough, and W. D. Collins, 2008: Radiative forcing by long-lived greenhouse gases: Calculations with the AER radiative transfer models.J. Geophys. Res., 113, D13103, https:// doi.org/10.1029/2008JD009944.

IPCC, 2013: Climate Change 2013: The Physical Science Basis. T. F. Stocker et al., Cambridge University Press, 1535 pp.
Kain, J. S., 2004: The Kain-Fritsch convective parameterization: An update. J. Appl. Meteor., 43, 170-181, https://doi.org/ 10.1175/1520-0450(2004)043<0170:TKCPAU>2.0.CO;2.

Kharin, V. V., F. W. Zwiers, X. Zhang, and G. C. Hegerl, 2007: Changes in temperature and precipitation extremes in the IPCC ensemble of global coupled model simulations. J. Climate, 20, 1419-1444, https://doi.org/10.1175/ JCLI4066.1.

$-, \ldots,-$, and M. Wehner, 2013: Changes in temperature and precipitation extremes in the CMIP5 ensemble. Climatic Change, 119, 345-357, https://doi.org/10.1007/ s10584-013-0705-8.

Kutzbach, J. E., J. W. Williams, and S. J. Vavrus, 2005: Simulated 21 st century changes in regional water balance of the Great Lakes region and links to changes in global temperature and poleward moisture transport. Geophys. Res. Lett., 32, L17707, https://doi.org/10.1029/2005GL023506.

Liang, X.-Z., and Coauthors, 2012: Regional climate-Weather Research and Forecasting Model. Bull. Amer. Meteor. Soc., 93, 1363-1387, https://doi.org/10.1175/BAMS-D-11-00180.1.

Lofgren, B. M., 1997: Simulated effects of idealized Laurentian Great Lakes on regional and large-scale climate. J. Climate, $\mathbf{1 0}$, 2847-2858, https://doi.org/10.1175/1520-0442(1997)010<2847: SEOILG $>2.0 . \mathrm{CO} ; 2$.

Meehl, G. A., F. Zwiers, J. Evans, T. Knutson, L. Mearns, and P. Whetton, 2000: Trends in extreme weather and climate events: Issues related to modeling extremes in projections of future climate change. Bull. Amer. Meteor. Soc., 81, 427-436, https://doi.org/ 10.1175/1520-0477(2000)081<0427:TIEWAC >2.3.CO;2.

_ , and Coauthors, 2012: Climate system response to external forcings and climate change projections in CCSM4. J. Climate, 25, 3661-3683, https://doi.org/10.1175/JCLI-D-11-00240.1.

Mesinger, F., and Coauthors, 2006: North American Regional Reanalysis. Bull. Amer. Meteor. Soc., 87, 343-360, https://doi.org/ 10.1175/BAMS-87-3-343.

Mironov, D., 2008: Parameterization of lakes in numerical weather prediction description of a lake model. COSMO Tech. Rep. 11, $41 \mathrm{pp}$.

Morrison, H., G. Thompson, and V. Tatarskii, 2009: Impact of cloud microphysics on the development of training stratiform precipitation in a simulated squall line: Comparison of oneand two-moment schemes. Mon. Wea. Rev., 137, 991-1007, https://doi.org/10.1175/2008MWR2556.1.

Muller, C. J., and P. A. O'Gorman, 2011: An energetic perspective on the regional response of precipitation to climate change. Nat. Climate Change, 1, 266-271, https://doi.org/10.1038/nclimate1169.

Nakanishi, M., and H. Niino, 2009: Development of an improved turbulence closure model for the atmospheric boundary layer. J. Meteor. Soc. Japan, 87, 895-912, https://doi.org/10.2151/ jmsj.87.895.

Niu, G.-Y., and Coauthors, 2011: The community Noah land surface model with multiparameterization options (Noah-MP): 1. Model description and evaluation with local-scale measurements. J. Geophys. Res., 116, D12109, https://doi.org/10.1029/ 2010JD015139.

Notaro, M., K. Holman, Z. Zarrin, E. Fluck, S. Vavrus, and V. Bennington, 2013: Influence of the Laurentian Great Lakes on regional climate. J. Climate, 26, 789-804, https://doi.org/ 10.1175/JCLI-D-12-00140.1.

_ V. Bennington, and S. Vavrus, 2015a: Dynamically downscaled projections of lake-effect snow in the Great Lakes basin. J. Climate, 28, 1661-1684, https://doi.org/10.1175/ JCLI-D-14-00467.1. 
, and B. Lofgren, 2015b: Dynamical downscaling-based projections of Great Lakes water levels. J. Climate, 28, 97219745, https://doi.org/10.1175/JCLI-D-14-00847.1.

Peltier, W. R., and G. Vettoretti, 2014: Dansgaard-Oeschger oscillations predicted in a comprehensive model of glacial climate: A "kicked" salt oscillator in the Atlantic. Geophys. Res. Lett., 41, 7306-7313, https://doi.org/10.1002/2014GL061413.

Scheff, J., and D. Frierson, 2012: Twenty-first-century multimodel subtropical precipitation declines are mostly midlatitude shifts. J. Climate, 25, 4330-4347, https://doi.org/10.1175/ JCLI-D-11-00393.1.

Scott, R. W., and F. A. Huff, 1997: Lake effects on climate conditions in the Great Lakes basin. Illinois Water Survey MCC Research Rep. 97-01, 73 pp.

Seager, R., N. Naik, and G. A. Vecchi, 2010: Thermodynamic and dynamic mechanisms for large-scale changes in the hydrological cycle in response to global warming. J. Climate, $\mathbf{2 3}$, 4651-4668, https://doi.org/10.1175/2010JCLI3655.1.
Skamarock, W., and Coauthors, 2008: A description of the Advanced Research WRF version 3. Tech. Note TN475+STR, 113 pp.

Tebaldi, C., K. Hayhoe, J. M. Arblaster, and G. A. Meehl, 2006: Going to the extremes. Climatic Change, 79, 185-211, https:// doi.org/10.1007/s10584-006-9051-4.

Van der Ent, R. J., H. H. G. Savenije, B. Schaefli, and S. C. SteeleDunne, 2010: Origin and fate of atmospheric moisture over continents. Water Resour. Res., 46, W09525, https://doi.org/ 10.1029/2010WR009127.

Wang, M., and J. E. Overland, 2012: A sea ice free summer Arctic within 30 years: An update from CMIP5 models. Geophys. Res. Lett., 39, L18501, https://doi.org/10.1029/ 2012 GL052868.

Xiao, C., B. M. Lofgren, J. Wang, and P. Y. Chu, 2016: Improving the lake scheme within a coupled WRF-lake model in the Laurentian Great Lakes. J. Adv. Model. Earth Syst., 8, 19691985, https://doi.org/10.1002/2016MS000717. 